\title{
Theoretical basis for convective invigoration due to increased aerosol concentration
}

\author{
Z. J. Lebo ${ }^{1}$ and J. H. Seinfeld ${ }^{1,2}$ \\ ${ }^{1}$ Environmental Science and Engineering, California Institute of Technology, Pasadena, 91125, CA, USA \\ ${ }^{2}$ Chemical Engineering, California Institute of Technology, Pasadena, 91125, CA, USA
}

Received: 3 January 2011 - Published in Atmos. Chem. Phys. Discuss.: 24 January 2011

Revised: 9 May 2011 - Accepted: 27 May 2011 - Published: 9 June 2011

\begin{abstract}
The potential effects of increased aerosol loading on the development of deep convective clouds and resulting precipitation amounts are studied by employing the Weather Research and Forecasting (WRF) model as a detailed high-resolution cloud resolving model (CRM) with both detailed bulk and bin microphysics schemes. Both models include a physically-based activation scheme that incorporates a size-resolved aerosol population. We demonstrate that the aerosol-induced effect is controlled by the balance between latent heating and the increase in condensed water aloft, each having opposing effects on buoyancy. It is also shown that under polluted conditions, increases in the $\mathrm{CCN}$ number concentration reduce the cumulative precipitation due to the competition between the sedimentation and evaporation/sublimation timescales. The effect of an increase in the IN number concentration on the dynamics of deep convective clouds is small and the resulting decrease in domain-averaged cumulative precipitation is shown not to be statistically significant, but may act to suppress precipitation. It is also shown that even in the presence of a decrease in the domain-averaged cumulative precipitation, an increase in the precipitation variance, or in other words, andincrease in rainfall intensity, may be expected in more polluted environments, especially in moist environments.

A significant difference exists between the predictions based on the bin and bulk microphysics schemes of precipitation and the influence of aerosol perturbations on updraft velocity within the convective core. The bulk microphysics scheme shows little change in the latent heating rates due to an increase in the $\mathrm{CCN}$ number concentration, while the bin microphysics scheme demonstrates significant increases
\end{abstract}

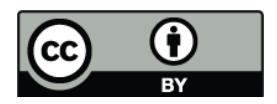

Correspondence to: Z. J. Lebo

(zachlebo@caltech.edu) in the latent heating aloft with increasing $\mathrm{CCN}$ number concentration. This suggests that even a detailed two-bulk microphysics scheme, coupled to a detailed activation scheme, may not be sufficient to predict small changes that result from perturbations in aerosol loading.

\section{Introduction}

Changes in ambient concentrations of cloud condensation nuclei $(\mathrm{CCN})$ and ice nuclei (IN) potentially alter cloud properties that may ultimately lead to modifications in cloud radiative forcing and/or precipitation. Traditionally, aerosolcloud interactions have been discussed primarily in terms of (IPCC, 2007): (1) The "1st aerosol indirect effect" (Twomey, 1977), in which all else being equal, an increase in the CCN number concentration will result in a higher cloud droplet number concentration and hence smaller particles. More numerous smaller particles act to increase the cloud optical depth and thus the cloud albedo that ultimately results in a reduction of the shortwave radiative flux that reaches the surface (cooling effect at the surface). (2) The " 2 nd aerosol indirect effect" (Albrecht, 1989), in which changes in the CCN number concentration may affect cloud lifetime and precipitation efficiency. An increase in the CCN number concentration will result in smaller cloud droplets, for which the collection kernels and collection efficiencies are substantially smaller in comparison to their larger counterparts, thus mitigating the collision-coalescence process and suppressing precipitation. Ultimately, the additional CCN particles are hypothesized to increase the longevity of the cloud and reduce the surface heating by shortwave radiation (cooling effect at the surface). With that said, it is now recognized that a division into the 1st and 2 nd indirect effects is

Published by Copernicus Publications on behalf of the European Geosciences Union. 
an oversimplification of the continuous cascade of processes that ensue in response to a perturbation in the aerosol number concentration.

Considerable attention has been given to the effects of aerosol particles on cloud properties for warm stratiform clouds (e.g., Ackerman et al., 2004; Lu and Seinfeld, 2006; Sandu et al., 2008; Hill et al., 2008, 2009; Wang and Feingold, 2009a,b; Wang et al., 2010). The extent to which these processes hold in mixed-phase and/or cold clouds is not well established. The ice phase presents significant complexities not present in warm clouds (i.e., riming, aggregation, accretion, heterogeneous and homogeneous freezing, melting, etc.), and the mixed-phase processes are the predominant mechanisms by which rain forms (not directly by collision-coalescence of liquid droplets into larger, rain drops). Recently, the potential effects of polluted environments on the formation and development of deep convective clouds have received attention via both modeling studies using a 3-D CRM with bulk microphysics (e.g., Van den Heever et al., 2006; Van den Heever and Cotton, 2007), 3-D CRM with bin microphysics (e.g., Khain et al., 2008; Khain and Lynn, 2009), 2-D CRM with bin microphysics (e.g., Fan et al., 2009) and, less commonly, observational analyses (e.g., Koren et al., 2005, 2010).

Conceptual hypotheses have been put forth by Rosenfeld et al. (2008a) and Stevens and Feingold (2009) for the invigoration of deep convective clouds by increased aerosol loading. These works are discussed in further detail below. Briefly however, via different reasoning, both works conclude that an increase in aerosol number concentration should act to increase surface precipitation. Rosenfeld et al. (2008a) suggest that a decrease in invigoration of deep convection may occur due to the direct effect of aerosols acting to limit the downward shortwave radiative flux at the surface, mitigating surface warming and leading to weaker convection. Although the ability for aerosol perturbations to invigorate deep convective clouds makes sense conceptually, modeling studies are still not in agreement as to the sign of the effect on precipitation owing to increased pollutants. For example, Van den Heever et al. (2006) showed using a 3-D CRM with bulk microphysics that adding aerosol particles in the form of CCN, giant CCN (GCCN), and/or IN causes a decrease in domain-average cumulative precipitation in reference to a clean environment observed during the Cirrus Regional Study of Tropical Anvils and Cirrus LayerFlorida Area Cirrus Experiment (CRYSTAL-FACE). On the other hand, Khain and Lynn (2009) demonstrated an increase in precipitation with an increase in $\mathrm{CCN}$ concentration using a spectral bin microphysics model but with low spatial resolution and abbreviated simulation time. In the same study, a decrease in precipitation with an increase in $\mathrm{CCN}$ number concentration was shown using a simple two-moment bulk microphysics scheme simulated on the same dynamic framework.
One can imagine though that the effect of an increase in the ambient aerosol concentration on surface precipitation (as well as cloud radiative forcing) in deep convective clouds may not be monotonic and likely depends significantly on the environmental conditions (i.e., Rosenfeld et al., 2008a). Khain et al. (2008) attempted to classify the effects of increased aerosol concentrations on precipitation for a wide range of cloud types and locations showing that, for example, deep convective clouds in dry environments should exhibit a decrease in precipitation with an increase in the aerosol number concentration. On the other hand, in moist environments, an increase in the aerosol loading was shown to increase precipitation or provide a negligible change depending on the specific cloud type. Moreover, Fan et al. (2009) studied the importance of the magnitude of the vertical wind shear on the aerosol-induced changes in deep convective clouds. The study showed that in a relatively high shear environment, an increase in the CCN number concentration produced a decrease in vertical velocity and cumulative precipitation.

Additional studies have looked at the potential implications of aerosol perturbations on the anvil cloud development and microphysical characteristics. The cloud resolving model (CRM) study of Van den Heever et al. (2006) showed that the anvil clouds atop the simulated deep convective clouds cover less area but contain higher amounts of condensed water when the aerosol number concentration is elevated. This results in more intense, localized precipitation. More recently, satellite data analysis has shown that regions with higher aerosol concentrations statistically correlate with areas of larger cloud extent, i.e., broader anvils (Koren et al., 2010). By broadening the anvil, the cloud becomes thinner and thus reduces the cloud albedo while the outgoing longwave radiation is relatively unchanged since the cloud top temperature does not change much. In turn, this combination results in an increase in the solar radiation reaching the surface. Little observational evidence is available at this time (due to the inherent complexities in measuring small concentrations of IN in regions of very high instability and remote locations) to determine clearly the overall effect of aerosol perturbations on anvil cloud development.

Measurements of IN number concentration were performed during CRYSTAL-FACE within a period of enhanced dust particle concentration (DeMott et al., 2003; Sassen et al., 2003). DeMott et al. (2003) reported that during CRYSTALFACE, IN number concentrations were observed to be as high as $1 \mathrm{~cm}^{-3}\left(10^{3} \ell^{-1}\right)$. Later, Van den Heever et al. (2006) and Teller and Levin (2006) demonstrated a decrease in precipitation with an increase in IN concentration using 3-D and 2-D CRMs, respectively. However, these studies do not fully represent the potential effects of IN on deep convective cloud development since the freezing process is parameterized based on the empirical relation of Meyers et al. (1992) in which the IN number concentration is expressed as an exponential function of temperature and/or supersaturation. For low temperatures (i.e., less than about $-30^{\circ} \mathrm{C}$ ), the 
IN number concentration, as predicted by the empirical relations, becomes erroneously large and will likely significantly impacts the model predictions.

Microphysical calculations of deep convective cloud (e.g., Khain et al., 2004, 2008; Teller and Levin, 2006; Khain and Lynn, 2009) and multi-cloud system (e.g., Lee and Feingold, 2010; Lee, 2011) invigoration in response to aerosol changes have been performed in recent years. Potential shortcomings exist in the method by which the $\mathrm{CCN}$ concentration is implemented and in the representation of the IN number concentration by the empirical Twomey (1959) relationship to predict the number of activated aerosol particles as a function of supersaturation. The empirical constants in this relation are specific to individual cloud types, i.e., the coefficients that apply for the convective core may not be adequate for other regions of the deep convective cloud, e.g., detrained stratocumulus. Moreover, some of the previous studies have used two-dimensional models (e.g., Khain et al., 2004, 2008; Teller and Levin, 2006) and others that have simulated all three dimensions (e.g., Khain and Lynn, 2009) have been performed at rather low spatial resolution, i.e., $\geq 2 \mathrm{~km}$ in the horizontal. It is natural to ask if with limited computational resources, should one simulate deep convective clouds using detailed bin microphysics or instead use a detailed twomoment bulk scheme at much higher spatial resolution? And, if one accounts for the activation of cloud droplets and nucleation of ice particles in a more physically coherent manner, what are the effects of aerosol particles on precipitation in deep convective clouds? These points are addressed in this study.

The remainder of this work is organized as follows: Sect. 2 presents hypotheses regarding aerosol effects on deep convective clouds. This is followed in Sect. 3 by a detailed description of the bulk and bin microphysics models that are employed in this study. Section 4 provides information relevant to the chosen dynamical model as well as details on the model initialization and simulations. Sections 5.1 and 5.2 discuss our findings regarding the influence of $\mathrm{CCN}$ and IN on deep convective clouds, respectively, and include a detailed comparison of the simulations performed with both the bulk and bin microphysics schemes. Moreover, Sects. 5.3 and 5.4 review the effects of aerosol perturbations on cloud top height and rainfall intensity, respectively. Lastly, Sect. 6 concludes the work and serves to outline the most important findings of this study.

\section{Theoretical basis and hypotheses}

Here, we highlight and discuss recent work in the realm of aerosol invigoration of deep convective cloud. Our purpose here is to present the relevant hypotheses related to this work in a concise framework.

\subsection{Rosenfeld et al. (2008a)}

Rosenfeld et al. (2008a) argue that the effect of an increased concentration of sub-cloud aerosol, and hence cloud condensation nuclei $(\mathrm{CCN})$, on convective clouds is to invigorate updrafts and produce an increase in precipitation as a result of upward heat transport via phase change. The argument is based on the results of a bulk thermodynamic parcel model, in which in the baseline simulation it is assumed that all water condenses and is immediately precipitated; hence, no energy is required to lift the hydrometeors (for the purpose of this study, hydrometeors are defined to be liquid cloud drops, pristine ice crystals, dendritic snow crystals, and rimed ice, or graupel). In other words, the work required, here in the form of mechanical energy, to lift condensed forms of water is zero. It is assumed, in addition, that the liquid water freezes at $-4{ }^{\circ} \mathrm{C}$ such that when the hydrometeors freeze at and above the level where this temperature is attained, a release of latent heat occurs, providing positive buoyancy. Rosenfeld et al. (2008a) argue that an increase in aerosol number concentration will serve to delay the onset of the collision-coalescence process, and energy is required to lift the parcel containing liquid hydrometeors to lower temperatures. Further increases in the aerosol concentration require the parcel to be lifted to even higher levels before collision-coalescence ensues. If collision-coalescence is delayed up to the freezing level, droplets are assumed to freeze, releasing latent heat, and then precipitating from the parcel, removing water mass and generating positive buoyancy. Hydrometeors are assumed to immediately freeze and precipitate if the parcel is lifted even farther. Rosenfeld et al. (2008a) argue that the addition of aerosol particles above that which would occur in a relatively clean environment (i.e., increasing the aerosol number concentration from $\approx 100 \mathrm{~cm}^{-3}$ to $\geq 1000 \mathrm{~cm}^{-3}$ ) can increase the released gravitational energy, which is equivalent to changing the effective convective available potential energy (CAPE) of the parcel by $>1000 \mathrm{~J} \mathrm{~kg}^{-1}$. The effect of the resultant increase in CAPE and mitigation of the collision-coalescence process is to delay the onset of precipitation, but increase the total precipitation. Rosenfeld et al. (2008a) also discussed that the increase in evaporative cooling within the downdrafts near the surface provides additional additional upward heat transport leading to convective invigoration.

The concentration of $\mathrm{CCN}$ required to delay collisioncoalescence until the parcel reaches the $-4^{\circ} \mathrm{C}$ isotherm is determined from the depth $(D)$ above cloud base needed for precipitation to begin as derived from aircraft measurements (Rosenfeld et al., 2008b; Freud et al., 2008; vanZanten et al., 2005). The result is an aerosol concentration of about $1200 \mathrm{~cm}^{-3}$, assuming standard values for tropical deep convective clouds. Since typical CCN concentrations tend to lie between 100 and $200 \mathrm{~cm}^{-3}$ and between 600 and $1700 \mathrm{~cm}^{-3}$ in clean and polluted marine regions, respectively (Andreae, 2009), the CCN concentration of $1200 \mathrm{~cm}^{-3}$ at 
which invigoration should reach a maximum is relevant for anthropogenically influenced locations. For concentrations of CCN above $1200 \mathrm{~cm}^{-3}$, collision-coalescence is delayed beyond the freezing level, more energy is required to lift the parcel, and the invigoration effect is mitigated. For higher $\mathrm{CCN}$ concentrations, less incoming solar radiation reaches the surface, reducing surface warming, which in turn, stabilizes the boundary layer, hence limiting convective development.

\subsection{Stevens and Feingold (2009)}

In addition to invigoration of updrafts within and below deep convective clouds, Stevens and Feingold (2009) proposed that an increase in $\mathrm{CCN}$ may act to increase cloud top height (i.e., cloud depth). The basis for this hypothesis is that an increase in $\mathrm{CCN}$ should act both to increase cloud droplet number concentration $\left(N_{\mathrm{c}}\right)$ and to reduce cloud droplet effective radius $\left(r_{\mathrm{e}}\right)$ in warm clouds, hence delaying the onset of precipitation. This allows hydrometeors to be advected to higher levels, increasing the amount of condensed water within the cloud, in turn increasing evaporation at cloud top, hence cooling and destabilizing the cloud top region. Updrafts near cloud top are invigorated, increasing cloud depth. Since deeper clouds are expected to have more liquid water, an increase in precipitation is expected. However, the microphysical complexity of cold clouds (i.e., those containing ice in some form) adds another dimension, hence the effect of increased aerosols no longer follows such a straightforward pathway.

\subsection{Khain et al. (2008)}

Khain et al. (2008) attempt to classify the effect of aerosol levels on precipitation from clouds of all types. Using a 2-D CRM with spectral microphysics, Khain et al. (2008) show that deep clouds in both tropical and moist urban areas tend to display an increase in precipitation with increasing aerosol levels. The effect of increased aerosol levels on supercell storms is shown to either decrease or increase precipitation depending upon whether the environment is dry or moist, respectively.

\section{Numerical simulation}

We explore the effects of aerosol perturbations on deep convective clouds by using the Weather Research and Forecasting (WRF) model Version 3.1 (Skamarock et al., 2008) as a CRM. The dynamical core of the WRF model is augmented by a detailed mixed-phase bin microphysics scheme following Tzivion et al. (1987), Tzivion et al. (1989), Feingold et al. (1988), Reisin et al. (1996), and Khain et al. (2004). In addition, we provide comparisons between predictions of the detailed bin model and those of a modified two-moment fiveclass (i.e., cloud, rain, pristine ice, snow, and graupel) bulk microphysics scheme (Morrison et al., 2005; Morrison and Pinto, 2005). The bin scheme and the modifications to the bulk scheme are described in detail below.

\subsection{Bin microphysics scheme}

The mixed-phase bin microphysics scheme divides each hydrometeor spectrum into 36 bins (i.e., $x_{j_{1}}, x_{j_{2}}, \ldots, x_{j_{36}}$, where $j$ corresponds to the hydrometeor type: $\mathrm{c}, \mathrm{i}, \mathrm{s}$, and $\mathrm{g}$ for liquid cloud droplets, pristine ice, snow, and graupel, respectively, and $x$ is the mass) with mass doubling between bins such that

$x_{k+1}=2 x_{k}$

in which $k$ corresponds to the lower boundary of bin number $k$. The mass of the smallest bin is defined to be $1.598 \times 10^{-14} \mathrm{~kg}$ (Reisin et al., 1996), which, for liquid droplets (with density $\rho_{1}=1000 \mathrm{~kg} \mathrm{~m}^{-3}$ ) corresponds to a diameter of $3.125 \mu \mathrm{m}$. Additionally, we assume fixed bulk densities for the frozen species, i.e., $\rho_{\mathrm{i}}=900 \mathrm{~kg} \mathrm{~m}^{-3}, \rho_{\mathrm{s}}=$ $200 \mathrm{~kg} \mathrm{~m}^{-3}, \rho_{\mathrm{g}}=500 \mathrm{~kg} \mathrm{~m}^{-3}$. The choice of 36 bins allows hydrometeors to attain appreciable sizes for precipitation to occur while minimizing the risk of creating numerical instability due to very large particles falling through grid boxes within a single time step. With these assumptions, the droplets, pristine ice, snow, and graupel can grow to $10.1 \mathrm{~mm}, 10.5 \mathrm{~mm}, 17.3 \mathrm{~mm}$, and $12.8 \mathrm{~mm}$, respectively. These sizes are adequate to accurately represent the formation of hail (i.e., large graupel) and the changes in hail formation due to aerosol perturbations that have been shown to be important in previous studies (e.g., Andrejczuk et al., 2004; Khain et al., 2011).

\subsubsection{Collision-coalescence, accretion, riming, and aggregation}

The collision-coalescence process is represented by the moment-conserving numerical solution to the stochastic collection equation of Tzivion et al. (1987) for the first two moments of each distribution, namely the number concentration $\left(N_{j_{k}}\right)$ and mass mixing ratio $\left(M_{j_{k}}\right)$. For collisions amongst liquid droplets, we use the Long (1974) collection kernel. For ice-ice, ice-snow, ice-graupel, snow-graupel, snow-snow, liquid-ice, liquid-snow, liquid-graupel, graupel-graupel collisions we use the gravitational collection kernel.

Collisions among liquid droplets simply produce larger droplets. As a result, the first moment of the size distribution, the mass, is conserved within the liquid category while the zeroth moment, the number concentration, is reduced. Collisions among other particles, e.g., ice-liquid, ice-ice, etc., are not as straightforward because the collisions may lead to the formation of particles in a different category. Hence, the gain and loss terms for each hydrometeor type and category must be determined following the rules defined in Table 1 (Reisin 
Table 1. Assumptions regarding hydrometeor collisions.

\begin{tabular}{lll}
\hline Collision & Result & Criterion \\
\hline Liquid-Liquid & Liquid & \\
Ice-Ice & Snow & \\
Snow-Snow & Snow & \\
Graupel-Graupel & Graupel & \\
Ice-Snow & Snow & \\
Ice-Graupel & Graupel & \\
Ice-Liquid & Ice & $m_{\mathrm{i}} \geq m_{1}$ \\
& Graupel & $m_{\mathrm{i}}<m_{1}$ \\
Snow-Graupel & Graupel & \\
Snow-Liquid & Snow & $m_{\mathrm{s}} \geq m_{1}$ \\
& Graupel & $m_{\mathrm{s}} \geq m_{1}$ \\
Graupel-Liquid & Graupel & \\
\hline
\end{tabular}

et al., 1996; Khain et al., 2004). Note that $m_{1}, m_{\mathrm{s}}$, and $m_{\mathrm{i}}$ correspond to the masses of the liquid, snow, and ice particles involved in a collision.

\subsubsection{Vapor condensation/deposition and evaporation/sublimation}

The simulation of condensation and evaporation of water to and from liquid drops, as well as deposition and sublimation, can depend strongly on the chosen time step and are highly sensitive to small fluctuations in the supersaturation (both with respect to liquid water as well as ice). Tzivion et al. (1989) formulated the condensational forcing $(\tau)$ due to a vapor surplus or deficit $\left(\Delta q_{\mathrm{v}}\right)$ as the integral of the surplus/deficit over a timestep $(\Delta t)$ as

$\tau=G(P, T) \int_{t}^{t+\Delta t} \Delta q_{\mathrm{v}} d t$

in which $G(P, T)$ is a known function of pressure $(P)$ and temperature $(T)$ defined in Pruppacher and Klett (1997) and Seinfeld and Pandis (2006) and $\Delta q_{\mathrm{v}}$ is defined as

$\Delta q_{\mathrm{v}}=q_{\mathrm{v}}-q_{\mathrm{s}}$

where $q_{\mathrm{s}}$ is the saturated water vapor mixing ratio. Due to condensation/evaporation and deposition/sublimation, and the resulting latent heating, within a timestep, $\Delta q_{\mathrm{v}}$ is not necessarily constant over the timestep. We use the method of Harrington et al. (2000) to predict the evolution of $q_{\mathrm{v}}$, and consequently, $\Delta q_{\mathrm{v}}$, over the course of each timestep. By utilizing Eq. (2) we can capture the changes in the vapor surplus within a timestep as a result of phase changes, i.e., condensation/evaporation and deposition/sublimation. The full solution to the condensation equation as derived by Tzivion et al. (1989) for linearized distributions within bins is cumbersome and computationally expensive. Therefore, we employ the method of Stevens et al. (1996) in which the mass and number within a given bin are distributed following a top hat distribution. Moreover, we include gas kinetic effects on the growth of the hydrometeors following Clark (1974) and Stevens et al. (1996) in which the mass growth equation can be expressed as

$\frac{d m}{d t}=\frac{m^{2 / 3}}{m^{1 / 3}+\ell} G(P, T) \Delta q_{\mathrm{v}}$

in which $\ell$ represents a length scale for vapor growth defined as

$\ell=\ell_{\circ}\left(\frac{4}{3} \pi \rho_{\mathrm{w}}\right)^{1 / 3}$

in which $\ell_{\circ}$ is assumed to be $6.4 \mu \mathrm{m}$. There exists an analytic solution to Eq. (4), and this solution is used for the remapping of the bins due to condensation/evaporation and deposition/sublimation.

\subsubsection{Cloud droplet activation and regeneration}

The aerosol size distribution is assumed to follow a singlemode lognormal distribution (Seinfeld and Pandis, 2006),

$n^{d}\left(D_{\mathrm{p}}\right) \equiv \frac{d N}{d \ln D_{\mathrm{p}}}=\frac{N_{\mathrm{a}}}{\sqrt{2 \pi} \ln \sigma} \exp \left[-\frac{\ln ^{2}\left(\frac{D_{\mathrm{p}}}{D_{\mathrm{g}}}\right)}{2 \ln ^{2} \sigma}\right]$

where, $N_{\mathrm{a}}$ is the total aerosol number concentration, $\sigma$ and $D_{\mathrm{g}}$ are the standard deviation and geometric mean diameter, respectively, and $D_{\mathrm{p}}$ is the particle diameter. For the purposes of this study, we let $D_{\mathrm{g}}=0.1 \mu \mathrm{m}$ and $\sigma=1.8$. The aerosol distribution is discretized into 36 mass-doubling bins. The first bin corresponds to an aerosol particle in which $D_{\mathrm{p}}=1 \mathrm{~nm}$. The total number concentration is set during the model initialization and the aerosol particles that remain after advection are advected throughout the domain. The number of activated aerosol particles $\left(N_{\text {act }}\right)$ is computed during each time step by integrating the size distribution over particles with critical supersaturations that are less than the ambient supersaturation,

$N_{\mathrm{act}}=\int_{0}^{S} n^{s}\left(s^{\prime}\right) d s^{\prime}$

where $S$ is the ambient supersaturation and $n^{s}\left(s^{\prime}\right)$ is the critical supersaturation distribution. The activated aerosols are removed from the corresponding aerosol bin and moved to the cloud droplet distribution. The activated size of the newly formed droplets is computed following Kogan (1991), Khain et al. (2000), and Xue et al. (2010) in which the activated droplet size is assumed to be a factor of $k\left(D_{\mathrm{p}}\right)$ larger than the aerosol of size $D_{\mathrm{p}}$. The smallest of the activated aerosols are assumed to enter the first bin of the droplet distribution whereas larger aerosols are moved to the bin corresponding to their predicted activated droplet size. Aerosol scavenging was shown to have a negligible effect on cloud properties by Geresdi and Rasmussen (2005) and is thus not included in the current scheme. The evaporation of cloud droplets leads 
to the regeneration of aerosol particles. Xue et al. (2010) demonstrated the significance of aerosol regeneration on cloud microphysical properties. Without including the regeneration of aerosols, the number of cloud droplets activated during a simulation can be erroneously underestimated thus increasing the mean size and ultimately leading to artificially enhanced precipitation. The number of aerosols that are formed in one timestep is assumed to be equivalent to the number of cloud droplets that evaporate following Xue et al. (2010). For the purposes of this study, we assume that the effect of collision-coalescence on the regenerated aerosol size distribution is negligible.

\subsubsection{Freezing and melting}

Supercooled cloud drops can freeze to form ice crystals via heterogenous (i.e., contact nucleation, immersion freezing, deposition freezing, etc.) and homogeneous freezing. We must turn to previous studies (Bigg, 1953; Fletcher, 1962; Vali, 1975; Cooper, 1986; Meyers et al., 1992) that have shown via various techniques that the ice nuclei (IN) number concentration (and inherently the number of frozen drops) can be diagnosed by empirically derived using the ambient environmental conditions. The expression derived by Bigg (1953) for the rate of change of frozen drops with time can be used to express the number of frozen drops in a bin during a time step $\left(N_{\mathrm{f}_{k}}\right)$ due to both homogeneous freezing of cloud droplets (for $T<-37^{\circ} \mathrm{C}$ ) and immersion freezing $\left(-37^{\circ} \mathrm{C}<T<-5^{\circ} \mathrm{C}\right)$ as (Reisin et al., 1996),

$N_{\mathrm{f}_{k}}=N_{\mathrm{c}_{k}}(t)\left(1-\exp \left[-\frac{\overline{m_{\mathrm{c}_{k}}}}{\rho_{\mathrm{l}}} A^{\prime} \exp \left(B^{\prime}\left(T_{\circ}-T\right)\right) \Delta t\right]\right)$

where $N_{\mathrm{c}_{k}}(t)$ is the number of cloud drops in bin $k$ at the start of the time step, $\overline{m_{\mathrm{c}_{k}}}$ is the average droplet mass in bin $k$, and $A^{\prime}$ and $B^{\prime}$ are constants defined as $10^{-4} \mathrm{~cm}^{-3} \mathrm{~s}^{-1}$ and $0.66 \mathrm{~K}^{-1}$, respectively, from Orville and Kopp (1977). The frozen mass in bin $k$ is simply $N_{\mathrm{f}_{k}} \overline{m_{\mathrm{c}_{k}}}$. Here, we use Eq. (8) only for homogeneous nucleation of ice crystals. The nucleation of ice crystals due to immersion freezing is caused by IN being immersed within a cloud droplet. These IN become active at various temperatures. Vali (1975) showed that the number of active immersion IN $\left(N_{\mathrm{im}}\right)$ can be expressed as a function of temperature in degrees Celsius $\left(T_{\mathrm{c}}\right)$ by

$N_{\mathrm{im}}=N_{\mathrm{im}_{\circ}}\left(0.1 T_{\mathrm{c}}\right)^{\gamma}$

in which it is assumed that $N_{\mathrm{im}_{\circ}}=10^{7} \mathrm{~m}^{-3}$ and $\gamma=4.4$ for convective clouds. Furthermore, for deposition and condensation freezing, we use the formula of Meyers et al. (1992) to relate the number of deposition and condensation IN $\left(N_{d}\right)$ to that of the ambient supersaturation with respect to ice $\left(S_{\text {ice }}\right)$ as

$N_{d}=N_{d_{\circ}} \exp \left[-0.639+12.96 S_{\text {ice }}\right]$

where $N_{d_{\circ}}=10^{-3} \mathrm{~m}^{-3}$. We distribute evenly the number of droplets that freeze due to deposition and contact freezing.
All frozen hydrometeors are assumed to melt over the course of a single timestep when the ambient temperature of the grid box containing such particles is greater than $0^{\circ} \mathrm{C}$. Sensitivity simulations with more sophisticated, and hence more computationally expensive, melting routines that attempt to account for heat transfer within the frozen species demonstrated a qualitatively insignificant change in the results presented here.

\subsubsection{Sedimentation}

All hydrometeors are assumed to sediment at their terminal fall speeds $\left(v_{\mathrm{t}_{j}}, j\right.$ corresponding to the particle type). As alluded to above, fall speeds for snow are computed from the mass-fall speed relationships determined by Locatelli and Hobbs (1974) for aggregates of unrimed side planes. For consistency, we use the same mass-fall speed relationships for graupel and hail as in the bulk microphysics scheme (Morrison et al., 2005; Morrison and Pinto, 2005). The mass-fall speed relationships for hail are used to predict sedimentation of particles in the tail of the graupel distribution. The terminal fall speed of ice crystals is computed following Heymsfield and Kajikawa (1987). For the purpose of this study, it is assumed that particles in the ice category are pristine crystals in the shape of thin hexagonal plates (type P1a). Terminal velocities are computed by relating the crystal Davies or Best number $(X)$ to the crystal Reynolds number $\left(N_{R e}\right)$ by (Heymsfield and Kajikawa, 1987),

$X=C_{\mathrm{d}} N_{R e}^{2}=\frac{2 m D_{\mathrm{i}}^{2} g}{\rho_{\mathrm{i}} v^{2} A}$

where $m$ is the crystal mass, $D_{\mathrm{i}}$ is the crystal dimension, $g$ is the acceleration due to gravity, $v$ is the kinematic viscosity of air, and $A$ is the crystal cross-sectional area normal to the direction of motion. Moreover, we can express $N_{R e}$ as

$N_{R e}=\frac{v_{\mathrm{t}_{\mathrm{i}}} D_{\mathrm{i}}}{v}$.

Using the $X-N_{R e}$ parameterization of Heymsfield and Kajikawa (1987), i.e.,

$N_{R e}=\alpha X^{\beta}$

and the definitions of $X$ and $N_{R e}$, we can write $v_{\mathrm{t}_{\mathrm{i}}}$ in terms of the crystal equivalent hexagonal diameter $\left(D_{\mathrm{i}_{\mathrm{eq}}}\right)$ as

$v_{\mathrm{t}_{\mathrm{i}}}=\frac{v \alpha}{D_{\mathrm{i}_{\mathrm{eq}}}}\left[\frac{2 m D_{\mathrm{i}_{\mathrm{eq}}}^{2} g}{\rho_{\mathrm{i}} v^{2} A}\right]^{\beta}$

where, for a hexagonal plate,

$A=\frac{3 \sqrt{3}}{2} D_{\mathrm{i}_{\mathrm{eq}}}^{2}$.

Lastly, Heymsfield and Kajikawa (1987) define $D_{\mathrm{i}_{\mathrm{eq}}}$ to be equivalent to $D_{\mathrm{i}} \sqrt{\gamma}$ where $\gamma$ is the crystal area ratio (i.e., the ratio of the crystal area to that of a crystal with the same dimensions). We take $\gamma=0.9$. 


\subsection{Bulk microphysical scheme}

For the two-moment bulk microphysics scheme, we use that of Morrison et al. (2005) and Morrison and Pinto (2005), included with the WRF model. The scheme has a fixed cloud drop number concentration $\left(N_{\mathrm{c}}\right)$, and the freezing process is parameterized following Cooper (1986). In order to more accurately represent the aerosol effect on cloud properties in the bulk model, we have modified the scheme to include explicit droplet activation as well as to include the freezing mechanisms included in the bin scheme described above. In other words, the aerosol population is initiated following a lognormal size distribution and binned into 36 mass doubling bins. The activated droplet size is computed as in the bin scheme and the total liquid water mixing ratio and number concentration that activate are computed and added to the bulk quantities. On the first timestep that aerosol particles are activated, the model fits a gamma distribution to the discretized droplet distribution. Computing the activation in this manner limits the differences between the bin and bulk schemes, especially pertaining to the link between $\mathrm{CCN}$ and cloud droplets (as well as IN and ice formation).

\section{Experimental setup}

The WRF model, modified as described in Sect. 3, is initialized with an idealized sounding typical for continental locales conducive to deep convective development (Figs. 1 and 2). Two soundings are used in order to analyze the extent to which an aerosol-induced effect on deep convection is dependent upon the ambient moisture content, i.e., the water vapor mixing ratio $\left(q_{\mathrm{v}}\right)$ or relative humidity $(\mathrm{RH})$. The ambient RH is permitted to change with height similar to that of Khain and Lynn (2009), except that in the present study, the $\mathrm{RH}$ at the surface is $95 \%$ in the moist scenarios and the $\mathrm{RH}$ for the drier scenarios is simply $5 \%$ less than that of the moist cases (hereinafter these scenarios are referred to as the highRH and lowRH simulations, respectively). Therefore, the RH at the surface is $90 \%$ for the lowRH simulations. Recently, Fan et al. (2009) showed that aerosol effects act to reduce precipitation in deep convective clouds in high shear environments. However, the purpose of this study is not to analyze the dependence of aerosol-induced invigoration of deep convective clouds on wind shear. As a result, we limit the vertical wind shear by utilizing the standard quarter circle shear wind profile derived from Weisman and Klemp (1982) (Fig. 2) so as not to influence the results by anomalously large vertical wind shear. Convection is initiated in the domain with a perturbation (bubble) in the potential temperature field of $3^{\circ} \mathrm{C}$ located in the center of the domain in the north-south direction, and offset to the west in the eastwest direction. The horizontal and vertical radii of the bubble are $10 \mathrm{~km}$ and $2 \mathrm{~km}$, respectively. Khain and Lynn (2009) looked at the dependency of the aerosol induced effects on

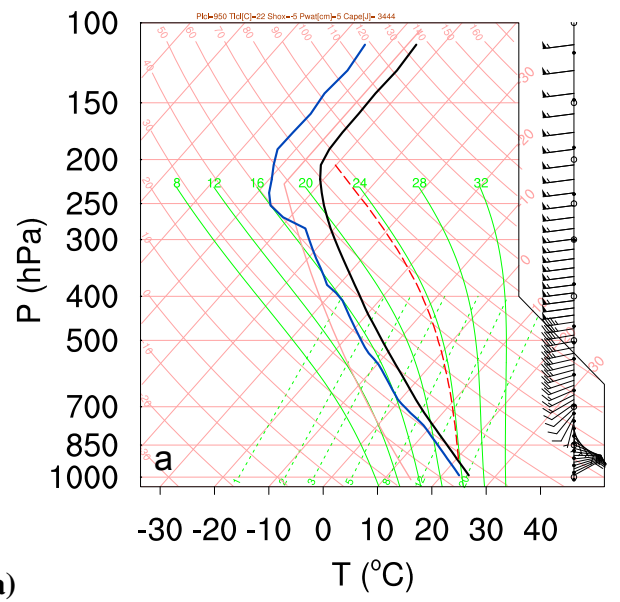

(a)

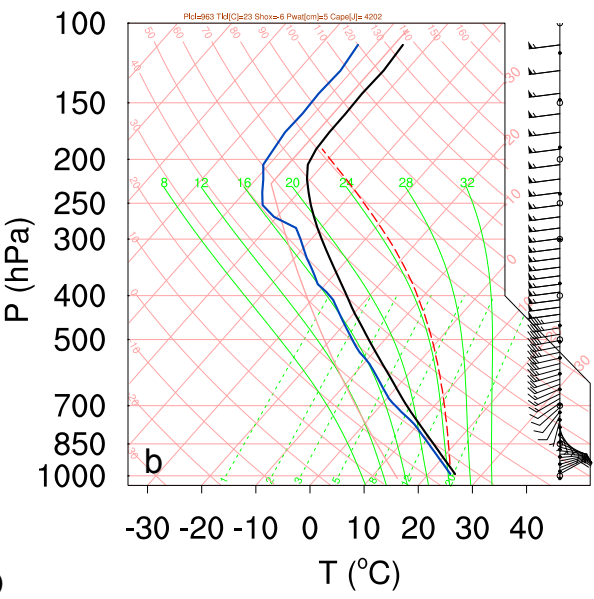

Fig. 1. Skew $T$-Log- $P$ diagrams of the initial temperature and moisture data for the (a) lowRH and (b) highRH simulations. The soundings are adopted from Khain and Lynn (2009) with modifications.

deep convective clouds using surface relative humidities of $95 \%$ and $85 \%$ for the moist and dry cases, respectively. We have increased the surface relative humidity in the lowRH cases since the cumulative domain-averaged precipitation in our simulations was insufficient to draw any definitive, statistically significant, conclusions at the lower RH.

It is important to note that unlike previous studies (e.g., Khain and Lynn, 2009), we choose to use a fixed timestep that is consistent for all simulations presented. Doing so does, in fact, increase the computation expense of performing such simulations (by nearly a factor of 2), in comparison to using an adaptive timestep method, in which a large fraction of each simulation is performed with a rather large timestep (i.e., at least twice that chosen here for the fixed timestep). However, the additional expense is necessary since the simulated results can differ both quantitatively and qualitatively when switching from a fixed timestep to an adaptive timestep method. In fact, simulations performed on a smaller domain demonstrate that the effect of even a small perturbation in the 


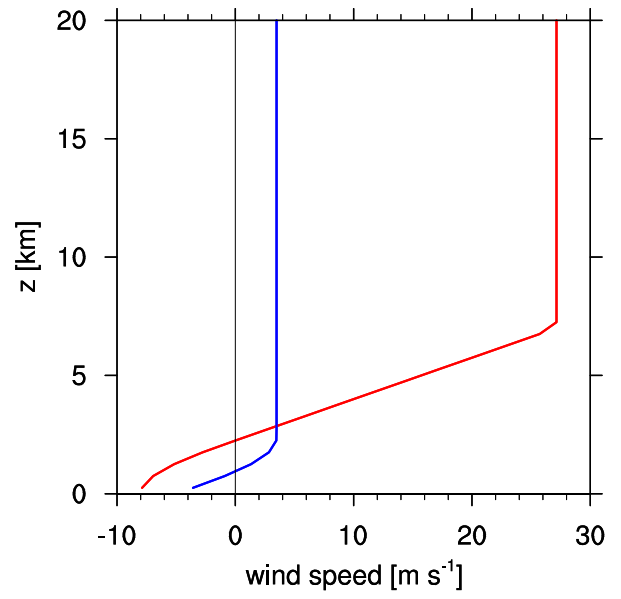

Fig. 2. Quarter circle shear wind profile. The zonal wind $(u)$ is in red and and the meridional wind $(v)$ is in blue. The values are derived following Weisman and Klemp (1982) as modified for inclusion in WRF.

ambient aerosol concentration (i.e., from 100 to $200 \mathrm{~cm}^{-3}$ ) can be qualitatively different when a fixed timestep is chosen over that where the timestep is allowed to evolve based upon the stability of the model itself. We find that it is necessary to used a fixed timestep to study the effect of aerosol perturbations on the stability of deep convective clouds because if the timestep is allowed to change with the model's stability, and the cloud contained within the polluted environment is in fact more unstable than its clean counterpart, the timestep will be smaller for the polluted simulation. Our sensitivity simulations show that the difference in the timestep can be as much as $2 \mathrm{~s}$ during the period of time in which convection is strongest. Since sedimentation is computed as simply the mass flux into and and out of a grid box multiplied by the timestep itself, the downward flux of condensed water integrated over a timestep is dependent upon the timestep. In other words, a longer timestep may allow more cloud water to fall out of a particular gridbox before other relevant microphysical processes can occur (i.e., collisions). Hence, the cumulative precipitation can be different between simulations with different aerosol number concentrations due to the difference in the timestep chosen by the model. To remove this uncertainty, we have chosen to fix the timestep at $4 \mathrm{~s}$ for all cases.

Another potential shortcoming of previous works (e.g., Fan et al., 2009; Khain and Lynn, 2009) is the choice of boundary conditions. Periodic boundary conditions are often used. However, CRM simulations of transient deep convective cells are not consistent with such boundary conditions. In other words, by choosing periodic boundary conditions, the western boundary of the domain is forced by the eastern boundary, which is physically implausible. We employ open boundaries, so that the advection of mass out of the eastern boundary does not affect the properties along the western boundary and thus artificially modify the cloud and ultimately precipitation patterns.

Many previous studies that have attempted to analyze aerosol-induced effects on deep convective clouds or compare spectral microphysics to bulk microphysics utilized twodimensional (2-D) models (e.g., Khain et al., 2004, 2008; Khain and Pokrovsky, 2004; Seifert et al., 2006; Phillips et al., 2007). We use a three-dimensional (3-D) domain. The horizontal domain length is $250 \mathrm{~km}$ in both the $x$ - and $y$-direction while the vertical domain extends from the surface to $20 \mathrm{~km}$. This vertical depth allows us to simulate into the lower stratosphere which is important for properly depicting anvil formation near the tropopause. The horizontal grid spacing is set to $1000 \mathrm{~m}$, and there are 60 stretched grid points in the vertical. The vertical grid spacing is less than $150 \mathrm{~m}$ at the surface and stretches to $400 \mathrm{~m}$ and $1500 \mathrm{~m}$ at $10 \mathrm{~km}$ above the surface and at the top of the model, respectively. A time step of $4 \mathrm{~s}$ is used to ensure numerical stability. The duration of the simulations is $6 \mathrm{~h}$. The duration of the simulations are limited by the domain size. In order to limit the effect of reflection off of the boundaries and or advection along the boundaries, we must limit the simulations to $6 \mathrm{~h}$. We understand that even at the resolution used in the current work, although higher than that of previous studies in which 3-D CRM simulations using bin microphysics was used, still higher resolution would be beneficial in order to fully capture the three-dimensional dynamical feedbacks and energetics resulting from changes in the cloud microphysics. However, the hard disk space and computational time required to perform such simulations with the bin microphysics model are beyond the magnitude of our current resources.

To analyze the potential effects of CCN and IN on deep convective clouds we perform a set of three simulations with varying concentrations of $\mathrm{CCN}$ and IN. These simulations are defined as: (1) "Clean" $-N_{\mathrm{CCN}}=100 \mathrm{~cm}^{-3}$, (2) "Semi-Polluted" - $N_{\mathrm{CCN}}=200 \mathrm{~cm}^{-3}$, and (3) "Polluted" $N_{\mathrm{CCN}}=500 \mathrm{~cm}^{-3}$. The "Clean" scenario will be used as the base case. To analyze the potential impact of changes in the aerosol loading when the added particles act as good IN, we perform additional simulations in which we multiply the predicted IN number concentrations for immersion, deposition, and condensation IN by a factor of 2 . Regardless of the microphysics scheme employed for the IN sensitivity tests, the CCN number concentration is doubled from the "Clean" case to $200 \mathrm{~cm}^{-3}$. Hereinafter, the cases with increased IN number concentrations are referred to as "IN-Polluted". The purpose of the "Semi-Polluted" and "IN-Polluted" cases is to show the effect of an increase in aerosol concentration when the particles act only as $\mathrm{CCN}$ and when they are $\mathrm{CCN}$ and IN, respectively.

In summary, the model used in the present study differs from those of previous works, (e.g., Fan et al., 2009; Khain and Lynn, 2009). First, we simulate the evolution of deep convective clouds at a much higher resolution than previous studies using a comparable CRM setup. It is prudent to 
increase the spatial resolution so as to capture the important dynamical feedbacks that may result from differential heating caused by phase changes. Moreover, one likely underestimates the maximum supersaturation within in a grid cell at coarse resolution. In order to predict the cloud drop number concentration, an accurate depiction of the supersaturation is required. We have addressed this issue in the modified bulk scheme by using the explicit activation of a bin-resolved aerosol population. Sensitivity simulations (not shown) exhibit large discrepancies in the bulk cloud water variables, cumulative precipitation, and dynamical feedbacks (i.e., the track of the deep convective cloud) between simulations at low resolution (i.e., $\Delta x=\Delta y \geq 2000 \mathrm{~m}$ ) and higher resolutions (i.e., $\Delta x=\Delta y<2000 \mathrm{~m}$ ). Moreover, we have updated the bin microphysics model of Reisin et al. (1996) to include more accurate collection kernels and collection efficiencies for riming processes. It is important to note that a key difference between in the bulk model employed in Khain and Lynn (2009) and the present study is that the prior used a fixed value for $N_{\mathrm{c}}$, while here we predict $N_{\mathrm{c}}$ based on relevant physics, aerosol number concentration, and ambient environmental conditions.

\section{Results: CCN and IN effects on deep convective clouds}

We begin with a comparison between bin and bulk simulations of the potential impact on deep convective cloud development and precipitation as a result of increasing the $\mathrm{CCN}$ number concentration. It is important to keep in mind that the purpose of this study is not to predict with great precision the amount of precipitation that may result from the given initial environmental conditions, but instead to numerically determine the extent to which the precipitation patterns and magnitude are altered in response to a modified aerosol loading. Unless stated otherwise, changes in the domainaveraged cumulative precipitation due to an increase in the $\mathrm{CCN}$ number concentration are statistically significant at the $\alpha=0.05$ significance level (where $\alpha$ denotes the significance level).

\subsection{CCN effects on precipitation and dynamical feedbacks}

\subsubsection{High relative humidity}

The overall effect of a perturbation in the CCN number concentration is to modify the precipitation amounting from a deep convective storm cloud. We quantify the effect as the domain-average cumulative surface precipitation in Fig. 3 (highRH simulations only). First, one notices that there is a discrepancy between the total precipitation predicted by the bulk scheme and that of the bin model.

One of the main differences in the inherent assumptions of both microphysics schemes is that the bulk scheme as-

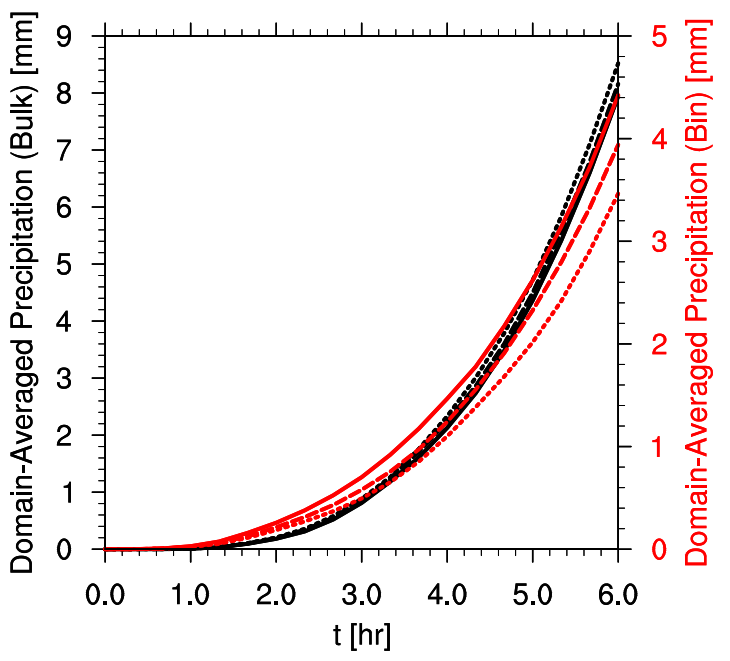

Fig. 3. Domain-averaged cumulative precipitation for the highRH simulations using the bulk (black) and bin (red) microphysics models. CCN effects are shown for the "Clean" (solid), "Semi-Polluted" (dashed), and "Polluted" (dotted) scenarios.

sumes prevents the existence of supersaturation within a gridbox after the microphysical calculations are performed. In other words, the bulk model includes a saturation adjustment scheme that removes excess water vapor at the end of each time step to reduce the saturation ratio to 1 . The bin model includes no such scheme. This difference in the underlying assumptions may force the bulk model to over-predict $q_{\mathrm{c}}$ and thus the total condensed water mixing ratio $\left(q_{\mathrm{t}}\right)$. The use of a saturation adjustment scheme in the bulk microphysics scheme is useful for low resolution simulations in which the time step is rather large (i.e., larger than the condensational growth timescale of the cloud particles). However, in a detailed CRM, such as the one presented in the current study, the time step is likely shorter than the condensational timescale of the cloud droplets (Chuang et al., 1997), hence the gridbox will remain supersaturated at the end of the timestep. As a result, the results of the bin model ought to be more accurate given the lack of a saturation adjustment scheme within the scheme. Moreover, the difference in precipitation between the simulations performed with each model is acceptable since the overarching goal of this work is to understand how precipitation is affected by changes in the CCN number concentration and not necessarily to fully explain the differences between simulations performed with bin and bulk microphysics.

In Figs. 4 and 5, cumulative precipitation after $2 \mathrm{~h}$ and $4 \mathrm{~h}$ of simulation time, respectively, is shown for the suite of scenarios described above under high RH conditions. The two largest differences between the bulk and bin simulations are that the magnitude of the cumulative precipitation near the storm's center is substantially higher for the simulations in which bin microphysics is employed and the precipitation 
Table 2. Domain-averaged cumulative precipitation at the completion of the simulations performed, $t=6 \mathrm{~h}$.

\begin{tabular}{lcccccc}
\hline Micro. & RH Profile & "Clean" Precip. & "Semi-Polluted" Precip. & $\Delta$ Precip. $^{\text {a }}$ & "Polluted" Precip. & $\Delta$ Precip. $^{\text {b }}$ \\
\hline Bin & highRH & $4.42 \mathrm{~mm}$ & $3.94 \mathrm{~mm}$ & $-10.9 \%$ & $3.46 \mathrm{~mm}$ & $-21.7 \%(-12.1 \%)$ \\
Bulk & highRH & $7.94 \mathrm{~mm}$ & $8.16 \mathrm{~mm}$ & $2.71 \%$ & $8.52 \mathrm{~mm}$ & $7.27 \%(4.45 \%)$ \\
Bin & lowRH & $2.39 \mathrm{~mm}$ & $2.25 \mathrm{~mm}$ & $-5.74 \%$ & $2.03 \mathrm{~mm}$ & $-14.9 \%(-9.74 \%)$ \\
Bulk & lowRH & $4.59 \mathrm{~mm}$ & $4.69 \mathrm{~mm}$ & $2.23 \%$ & $4.85 \mathrm{~mm}$ & $5.79 \%(3.49 \%)$ \\
\hline
\end{tabular}

a The relative change in the domain-averaged cumulative precipitation ( $\Delta$ Precip.) is computed for the "Semi-Polluted" case compared with that of the "Clean" case.

b $\Delta$ Precip. is computed for the "Polluted" case compared with that of the "Clean" case. $\Delta$ Precip. between the "Polluted" and "Semi-Polluted" cases is given in parentheses.

(a)

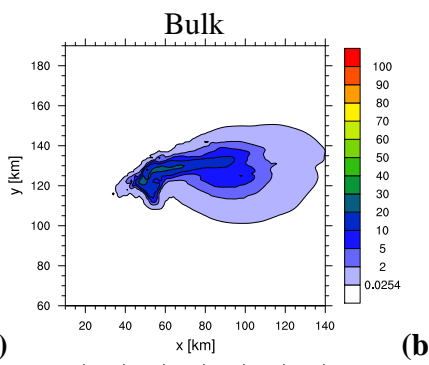

(c)

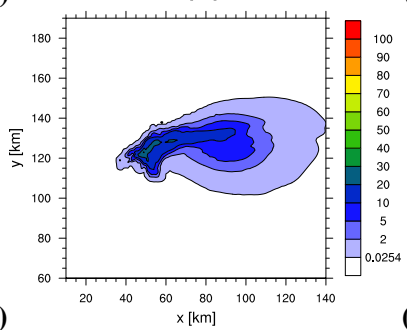

(b)
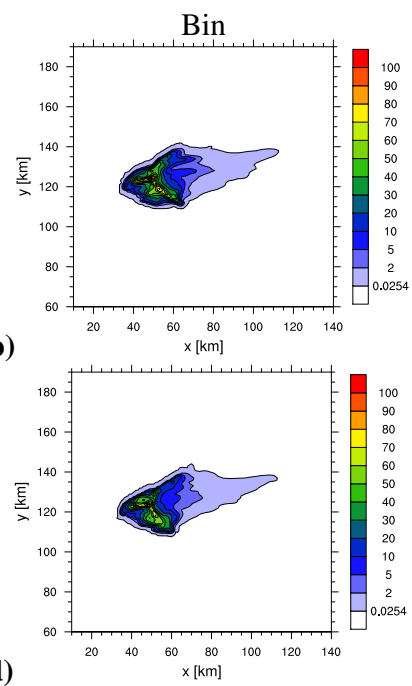

(a)

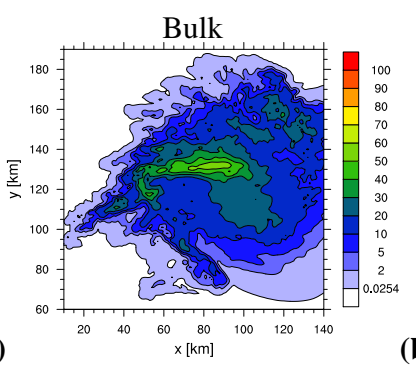

(b)

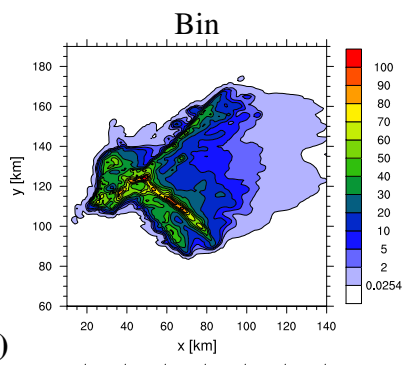

(c)
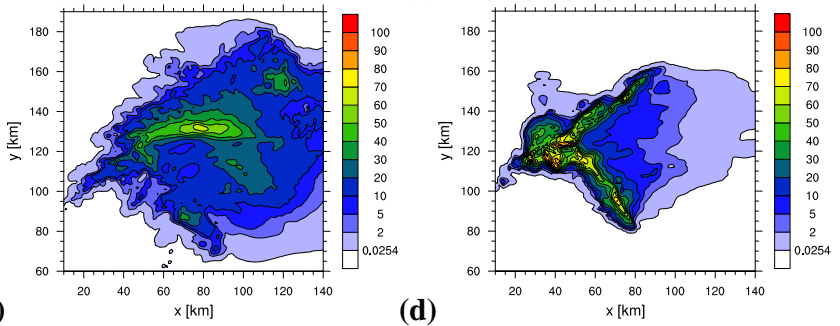

(e)

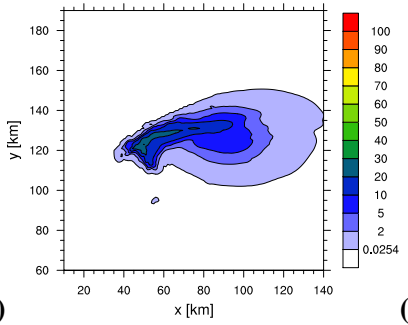

Fig. 4. Cumulative precipitation after $2 \mathrm{~h}$ of simulation time for the (a and b) "Clean", (c and d) "Semi-Polluted", and (e and f) "Polluted" scenarios for high RH. Simulations performed with bulk microphysics are shown in (a, c, and e) and those with bin microphysics in (b, $\mathbf{d}$, and $\mathbf{f})$. Note that the $x$ - and $y$-axes represent the grid location index and that the portrayed region is a subset of the entire domain, chosen to elicit the largest differences amongst the set of simulations performed. The first contour level is chosen to be $0.0254 \mathrm{~mm}$, which corresponds to 0.01 in. Any rainfall below this amount is considered to be a trace amount. Consequently, areas shown in white represent regions in which a trace or less of precipitation as fallen.

pattern also differs. The latter is seen by comparing, e.g., Fig. 5a (bulk) and b (bin) in which we find that the simulation run with bulk microphysics predicts a different trajectory for the northern branch of the system. As the cell splits, the
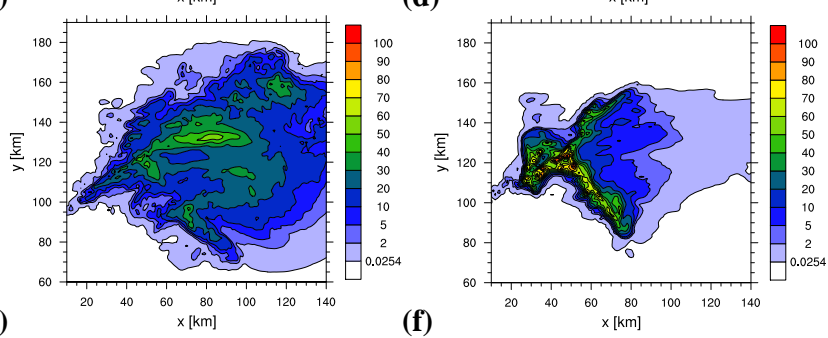

Fig. 5. As in Fig. 4 except after $4 \mathrm{~h}$ of simulation time.

northern cell follows a trajectory more towards due east in the bulk simulation while following a path toward the northeast in the bin simulation. The difference in storm trajectory is likely due to dynamical differences between the two systems, i.e., differences in latent heating and the inherent dynamical feedbacks. The latent heating effects will be discussed in more detail below. However, in general, these differences may be a result of using a simplified approach in a high-resolution model. In other words, as one reduces the model resolution, it should be expected that the deviation of $q_{\mathrm{c}}$ and $N_{\mathrm{c}}$ from some mean state should be reduced, such that the extremes (maxima) are not as large. As a result, autoconversion will then be reduced and precipitation will ultimately be reduced. Therefore, in order to accurately predict 
the total precipitation using a bulk microphysics model, subgrid scale fluctuations should be considered using methods like that proposed by Morales and Nenes (2010) to calculate precisely sub-grid scale supersaturations.

Figure 3 shows the domain-averaged cumulative precipitation for the highRH simulations. With the discrepancy between the total amount predicted by the bin model in comparison to that of the bulk scheme aside, we focus on the effect of increased CCN number concentrations on precipitation in each model. The overall effect of a doubling of the CCN number concentration (i.e., from 100 to $200 \mathrm{~cm}^{-3}$ ), using the bin microphysics scheme, is to decrease precipitation by $10.9 \%$ (Table 2). We find that a further increase in $\mathrm{CCN}$ number concentration (i.e., from 200 to $500 \mathrm{~cm}^{-3}$ ) causes a further reduction in precipitation predicted using the bin microphysics model, contrary to that which is suggested by the theoretical arguments of Rosenfeld et al. (2008a). Here lies an additional discrepancy between the two microphysics schemes, since the effect of an increase in $\mathrm{CCN}$ acts to increase the precipitation predicted by the bulk model. This point will be discussed in more detail below.

In order to understand theoretically how an increase CCN number concentration acts to decrease precipitation from deep convection, we turn our attention to the dynamics of the cloud first to look at the possible invigoration or suppression of convection. We can analyze the invigoration that may result from increased aerosol loading using the buoyancy $(B)$ equation (Houze, 1993):

$B=g\left[\frac{T^{\star}}{T_{\mathrm{a}}}-\frac{p^{\star}}{p_{\circ}}+0.61 q_{\mathrm{v}}^{\star}-q_{\mathrm{t}}\right]$

where $T^{\star}$ is the perturbed temperature from the ambient state $\left(T_{\mathrm{a}}\right), p^{\star}$ is the pressure perturbation from the base state $\left(P_{\circ}\right)$, $q_{\mathrm{v}}^{\star}$ is the deviation in the ambient water vapor mixing ratio from the reference state, and $q_{\mathrm{t}}$ is the total condensed water mass mixing ratio. From Eq. (16), we see that changes in aerosol concentration can be linked to changes in buoyancy, and consequently vertical velocity, since perturbing the $\mathrm{CCN}$ number concentration will lead to changes in $q_{\mathrm{t}}$ and $T^{\star} / T_{\text {a }}$ (through latent heating). However, the effects are counteractive, since an increase in CCN number concentration will increase the number of particles that reach the freezing level, freeze, and grow via vapor deposition, thus increasing the latent heating aloft (i.e., increasing buoyancy). But, the increased heating comes in part from an increase in vapor deposition and thus acts to also increase the $q_{\mathrm{t}}$ (decreasing buoyancy). We see then that if the increase in latent heating outweighs the increase in $q_{\mathrm{t}}$ the cloud will be invigorated. While, on the other hand, if vapor deposition is at least as large as the heating influence on the ambient air, the contributions to buoyancy can be offset and thus no invigoration (or potentially even a decrease in buoyancy) can theoretically occur.

To understand how the performed simulations represent potential changes in buoyancy we show $q_{\mathrm{t}}$ in Fig. 6, sepa- (a) $t=2 \mathrm{hr}$

(c) $t=4 \mathrm{hr}$

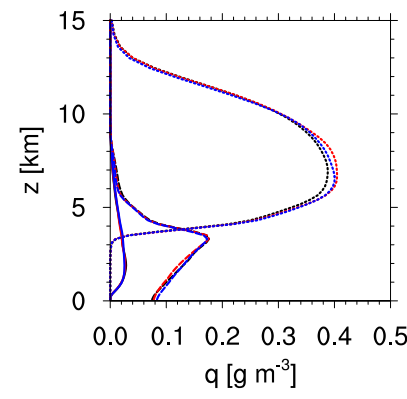

(e) $t=6 \mathrm{hr}$

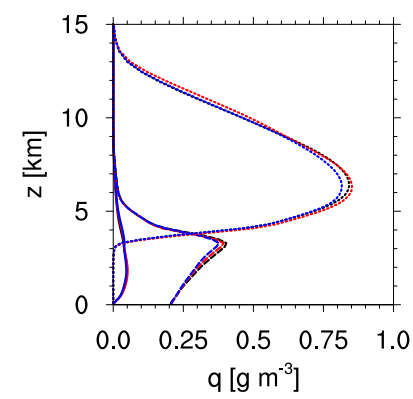

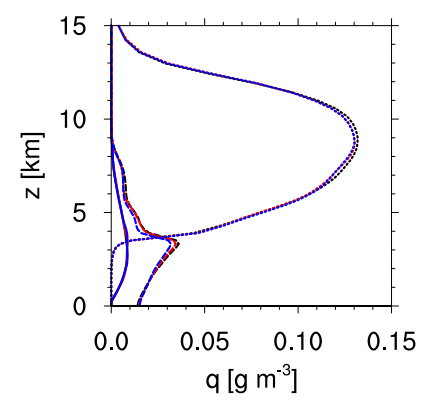

(b) $t=2 \mathrm{hr}$

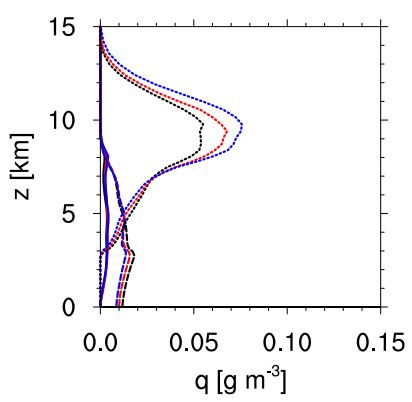

(d) $t=4 \mathrm{hr}$

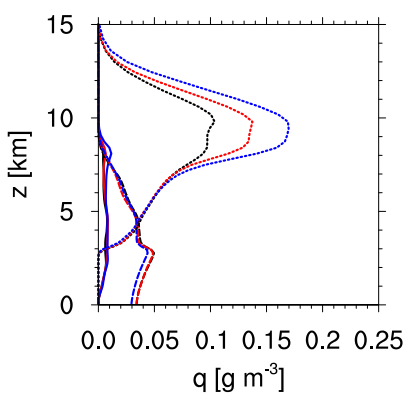

(f) $t=6 \mathrm{hr}$

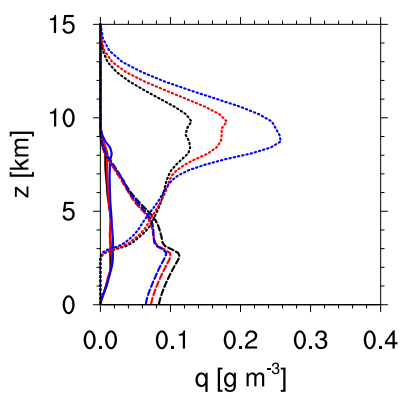

Fig. 6. Hourly domain-averaged cloud (solid), rain (dashed), and ice (dotted) water contents for the bulk (left) and bin (right) simulations. The aerosol sensitivity is shown for the "Clean" (black), "Semi-Polluted" (red), and "Polluted" (blue) scenarios. Note that the $x$-axes are different in order to clearly demonstrate changes in the bulk cloud properties with time and increased aerosol loading. Simulation time is shown in the subcaptions.

rated into cloud (solid), rain (dashed), and ice (dotted) water contents. This allows us to analyze the effect of increased aerosol loading on rain water simultaneously. From top to bottom, Fig. 6 shows the evolution of the vertical structure of the deep convective cloud in which initially, cloud water is lofted deep into the mixed-phase region, and the ice exists predominantly above $5 \mathrm{~km}$ in the bulk simulations and higher yet in the bin simulations. As time progresses, the condensed mass sediments, ice melts to form liquid droplets that act to increase the rain water mixing ratio. As a result, we see that in the bin simulations, the rain water content is 
suppressed initially while the cloud water content is slightly enhanced (Fig. 6b, d, and f). This is a direct result of the fact that smaller particles are less likely to collide, hence reducing the amount of cloud water converted to rain drops, and since the droplets are smaller, their terminal fall speeds are reduced and can be lofted higher in the atmosphere. On the contrary, the bulk model shows a small increase in $q_{\mathrm{r}}$ below the melting level (Fig. 6a, c, and e) As time progresses, the peak in the vertical distribution of ice water shifts downward, hence increasing the amount of melt water below the freezing water, ultimately leading to an enhancement in the rain water content for an increase in the $\mathrm{CCN}$ number concentration from the bulk model. However, even after $6 \mathrm{~h}$, the bin model shows that $q_{\mathrm{r}}$ is still suppressed in the cases with elevated CCN number concentrations in comparison to the "Clean" case. This prolonged suppression is discussed in detail below.

In order to describe how an increase in the $\mathrm{CCN}$ number concentration can alter the rain water content by a dynamical feedback, we turn to Fig. 7a and b, in which the mean vertical velocity $(w)$ within the convective core after $2 \mathrm{~h}$ of simulation time is shown for all highRH simulations. Here, we define the convective core to contain columns within which the mean vertical velocity between $3.3 \mathrm{~km}$ and $11 \mathrm{~km}$ is at least $1 \mathrm{~m} \mathrm{~s}^{-1}$. Any significant dynamical invigoration or suppression should appear from such an average. We see that an increase in the $\mathrm{CCN}$ number concentration produces a decrease in $w$ is more or less fixed for the simulations using the bulk microphysics scheme (Fig. 7a and b). However, the bin results show a slight enhancement in $w$ on the order of $5 \%$ to $15 \%$ within the warm sector of the cloud (i.e., below about $4 \mathrm{~km}$ ) due to increases in the CCN number concentration. In conjunction with the fact that the cloud droplets are smaller, hence more likely to be lofted into the mixed-phase region of the cloud and freeze, thus increasing the rate of vapor deposition, this enhancement in $w$ helps increase $q_{\mathrm{i}}$ and consequently, $q_{\mathrm{t}}$ (Fig. 6b, d, and f).

To confirm that additional vapor deposition is the root cause for the changes in $B$ and hence, $w$, we show domainaveraged latent heating rates in Fig. $7 \mathrm{c}$ and $\mathrm{d}$ for the suite of simulations performed. The simulations performed with the bulk microphysics scheme (i.e., Fig. 7c) illustrate that the change in latent heating due to changes in $\mathrm{CCN}$ number concentration is quite small, regardless of the magnitude of the CCN perturbation nut negative. From Eq. (16) we would expect that such a small change would result in a small decrease in $w$ assuming that $q_{\mathrm{t}}$ were fixed and if $q_{\mathrm{t}}$ were to have increased, the possibility for a further decrease in $w$ exists. Since, from Fig. 6, we see that $q_{\mathrm{t}}$ increases when the CCN number concentration is elevated, the result is a decrease in $w$ (Fig. 7a and b). In short, the bulk model suggests a limited convective suppression due to increases in CCN number concentration, but does exhibit signs of enhanced precipitation at the surface due to increasing the condensed mass within the mixed-phase region of the cloud.
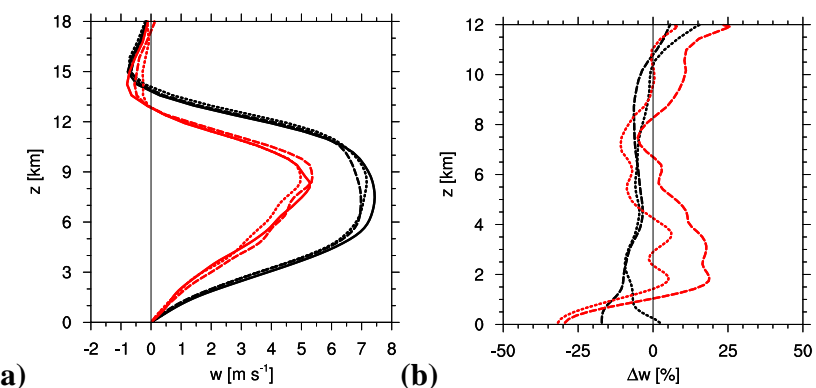

(a)
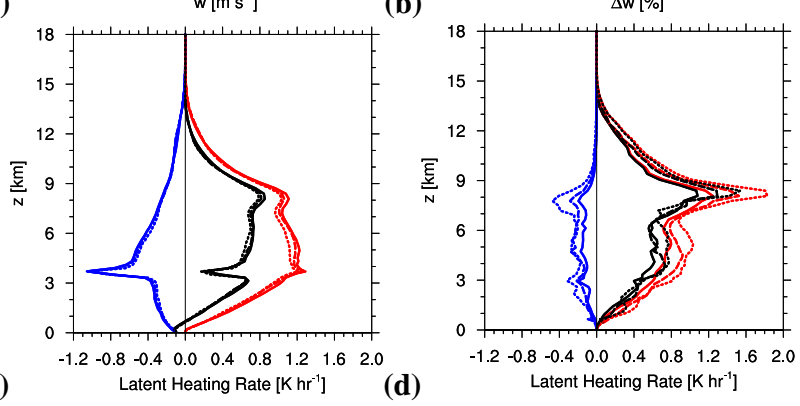

Fig. 7. (a) Average of the vertical velocity profile within the convective core and (b) the change in the mean vertical velocity due to changes in $\mathrm{CCN}$ number concentration. The convective core is defined to contain the columns in which the mean vertical velocity is more than $1 \mathrm{~ms}^{-1}$. Bulk (black) and bin (red) are displayed on the same graph. The differences are performed for the "Semi-Polluted" (dashed) and "Polluted" (dotted) cases relative to the "Clean" (solid) case. (c) and (d) show the latent heating rates for the bulk and bin model simulations, respectively. The net heating rate (black) is separated into warming (red) and cooling (blue). The vertical axes are different so as to highlight the differences within the cloud itself and because the relative differences at cloud top and above are much larger than those within the cloud. Simulation time is shown in the subcaptions.

On the other hand, the latent heating rate for the simulations performed with the bin microphysics scheme elicit a different result. Here, in Fig. 7d we see that an increase in the $\mathrm{CCN}$ number concentration (solid to dashed or dotted curves) results in an increase in the latent heating and, to a lesser extent, cooling (at some levels, the changes do offset, but, for the most part, the net heating rate increases). The overall result is an increase in the net latent heating rate. This increase in heating outweighs the negative effect on buoyancy owing to the increase in condensed liquid water in the warm sector of the cloud (Fig. 6) and consequently, we find an increase in $w$ (Fig. 7b) below $4 \mathrm{~km}$. The increase in $w$ shows that the convective cloud's dynamics are enhanced at low levels. On the other hand, within the mixed-phase region of the cloud and above, there is a negligible change in $w$ (Fig. 7b) even though there is an increase in the net latent heating rate (Fig. 7d). The reason for this lies in the large increase in $q_{\mathrm{i}}$ and thus $q_{\mathrm{t}}$ within this region (Fig. 6b, d, and f). This increase in $q_{\mathrm{t}}$ acts to outweigh the invigoration effect of an increase in latent heating. 
The following question is then suggested: why does an increase in $\mathrm{CCN}$ number concentration elicit a different response in precipitation in the bin microphysics simulations? And, why is the change in precipitation of a different sign for the bulk and bin microphysics simulations? As noted above, the bulk simulations produce a small change in latent heating rates (Fig. 7c) and consequently a slight decrease in $w$ (Fig. 7b). Thus, dynamically, the cloud is not invigorated and the resulting increase in precipitation arises from simply a mass balance argument, i.e., what goes up must come down (assuming that the evaporation of cloud/rain water and sublimation of ice/snow/graupel water is small). In other words, the cumulative precipitation increase results from simply adding more condensed water to the system aloft, that ultimately falls to the ground as precipitation. Conversely, we find that the bin model predicts changes to the dynamical nature (and microphysics, to be discussed below) of the convective system that provide a different response to an increase in $\mathrm{CCN}$ number concentration.

If we focus our attention on the bin microphysics simulations, Fig. 6 portrays an increase in $q_{\mathrm{i}}$, and consequently $q_{\mathrm{t}}$, for an increase in the $\mathrm{CCN}$ number concentration to $500 \mathrm{~cm}^{-3}$ that is over and above that which we find for the increase in $\mathrm{CCN}$ to $200 \mathrm{~cm}^{-3}$. Since the cloud droplets are even smaller in the "Polluted" case, even more droplets reach the freezing level at which point they freeze and grow via vapor deposition. This leads to an increase in condensed mass due to an increase in deposition. Figure $7 \mathrm{~d}$ shows that the latent heating is increased above $7 \mathrm{~km}$ for the "Polluted" case in comparison with both the "Clean" and "SemiPolluted" cases. If all else were equal between the "Polluted" and "Semi-Polluted" cases, we would expect to find an increase in $w$ and thus invigoration. However, Fig. 7d demonstrates that the increase in warming is offset by a substantial increase in cooling above $7 \mathrm{~km}$. Since the particles are smaller (the increase in number and mass is not linear), they are more readily evaporated/sublimated. Therefore, the ice particles are lofted high into the cloud, at which point they can be advected away from the core (smaller particles have a smaller terminal fall speed and thus can remain aloft for more time) and sublimate as they are detrained from the cloud top/anvil region. As a result, the increase in $q_{\mathrm{t}}$ for the increase in CCN number concentration moistens the mid- to upper-troposphere rather than increasing precipitation. In other words, as one moves towards a "Polluted" environment, the aerosol-induced effect on deep convection lies in the subtle competition between sedimentation and evaporation/sublimation timescales. Here, the latter is decreased whilst the former is increased, thus providing even more time for particles to evaporate on their way to the surface, resulting in what appears to be a positive feedback loop according to the bin simulations. In order to demonstrate the effect of reduced particles sizes on sedimentation, we use the radar reflectivity factor $(Z)$ in dBZ as shown in Fig. 8 at $2 \mathrm{~h}$ into the simulations. Here, $Z$ is defined as
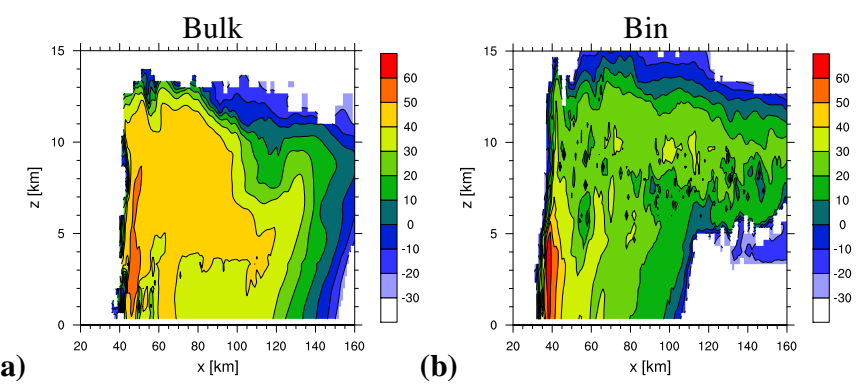

(a)

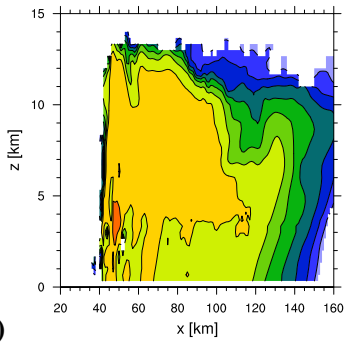

(c)

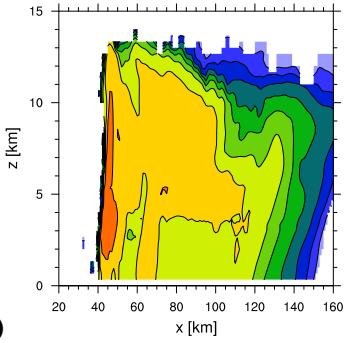

b)

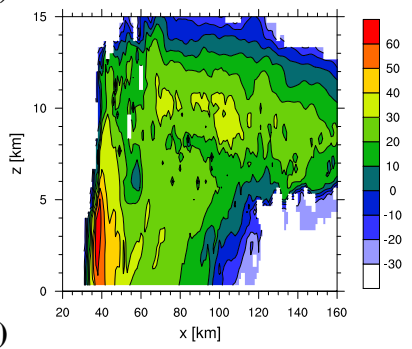

(e)

Fig. 8. Zonal vertical transects of the radar reflectivity factor $(Z)$ in dBZ. The transects are taken after 2 hours of simulation for $y=125 \mathrm{~km}$. (a, c, and e) are for the simulations with bulk microphysics and (b, d, and f) are for the simulations with bin microphysics. The "Clean" (a and b), "Semi-Polluted" (c and d), and "Polluted" (e and f) cases are shown.

$Z=10 \log \left[\sum_{j} \int_{0}^{\infty} N_{j} D_{\mathrm{j}}^{6} d D_{\mathrm{j}}\right]$

where $j$ denotes the different hydrometeor types. After a little algebra, we can write Eq. (17) as

$Z=10 \log \left[\sum_{j} \frac{6}{\pi} \int_{0}^{\infty} \frac{\rho_{j}}{\rho_{\mathrm{a}}} q_{\mathrm{j}} D_{\mathrm{j}}^{3} d D_{\mathrm{j}}\right]$

where $\rho_{\mathrm{a}}$ is air density. We see that changes in $Z$ can be directly related to changes in the mixing ratios of the hydrometeors. From Fig. 8b, d, and f, we see that aloft, i.e., in the upper region of the convective core and within the anvil, there is nearly no change in $Z$. But, from Fig. $6 \mathrm{~b}$, d, and $\mathrm{f}$, there is a consistent increase in condensed water aloft, especially in $q_{\mathrm{i}}$. Thus, if $q_{\mathrm{i}}$ increases due to increased aerosol loading, while $Z$ remains nearly fixed, the particles $D_{\mathrm{i}}$ must be smaller. Hence, the ice falls slower and the ultimate effect is to decrease the melting rate and decrease the domainaveraged cumulative precipitation. 


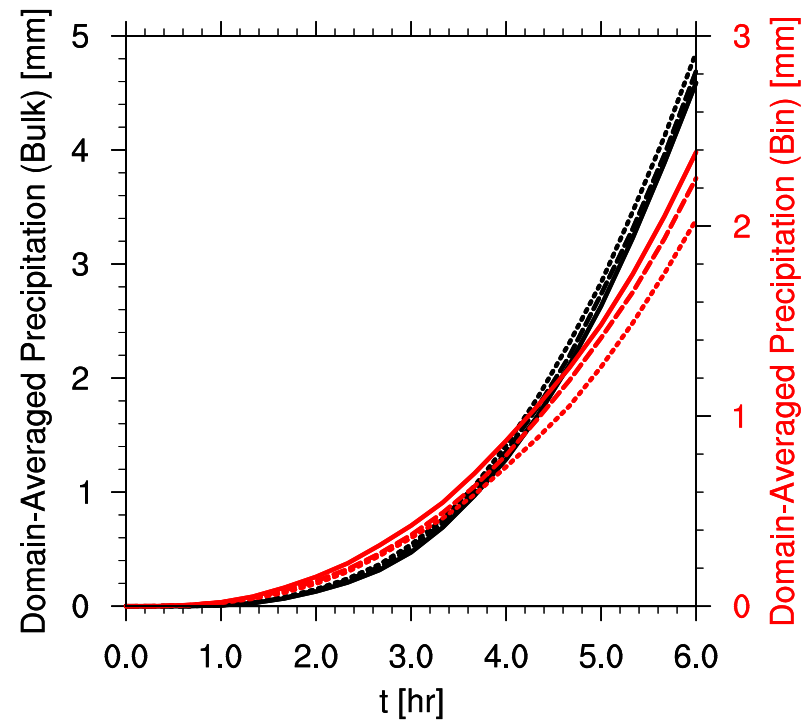

Fig. 9. Same as in Fig. 3 except for the lowRH simulations.

Figure 8 also sheds more light on the differences between the simulated bin and bulk model results. In general the maximum $Z$ in each simulation is nearly the same. However, the region of high reflectivity in the bulk results, i.e., $Z>30 \mathrm{dBZ}$, is much wider (by a fact or 2 to 3 ). This results from precipitation from the anvil region of the storm and is likely due to the saturation adjustment assumption mentioned above. From Fig. 8 it also becomes clear that the swath of heavier precipitation predicted by the bulk model is relatively unchanged due to increased aerosol loading (i.e., the width of the region in which $Z>30 \mathrm{dBZ}$ is nearly fixed) while the bin simulations suggest otherwise. The influence of aerosol loading on rainfall intensity will be discussed in more detail below.

\subsubsection{Low relative humidity}

It has been suggested that various environmental parameters, e.g., vertical wind shear (Fan et al., 2009), ambient relative humidity (Khain et al., 2008; Khain and Lynn, 2009), etc., may influence the aerosol-induced effect on deep convection. Here we extend the work of Khain et al. (2008) and Khain and Lynn (2009) by analyzing the effect on the aerosol-induced invigoration discussed above due to a small change in ambient relative humidity. It was shown previously that a reduction in the RH by $10 \%$ throughout the sounding may act to limit any invigoration, or in fact weaken the convective cloud when aerosols are added to the system. Here, we have reduced the RH by just $5 \%$ (Fig. 1b) to ensure that deep convection forms in all cases, and we permit the simulations to run for $12 \mathrm{~h}$, in order to encapsulate the period of time in which the rain rate attains a maximum.

From Fig. 9, we see that like in the highRH cases, precipitation is suppressed in the bin simulations and enhanced
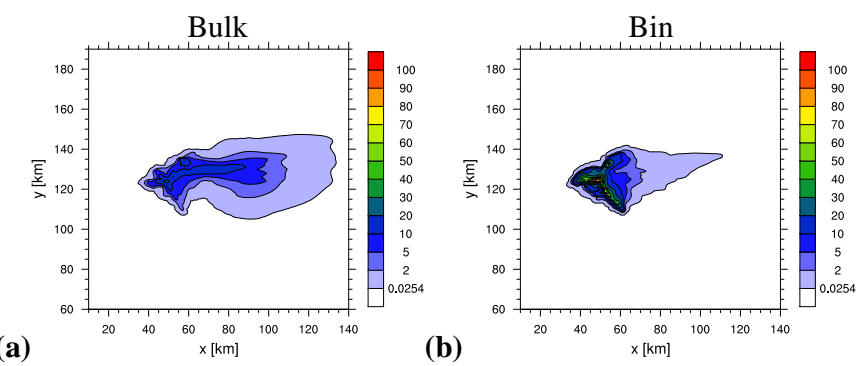

(a)

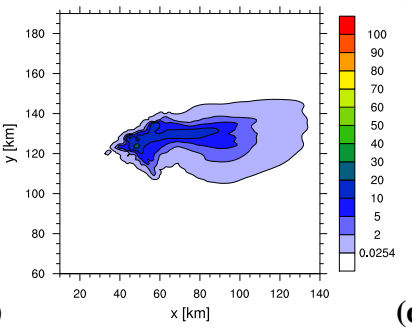

(c)

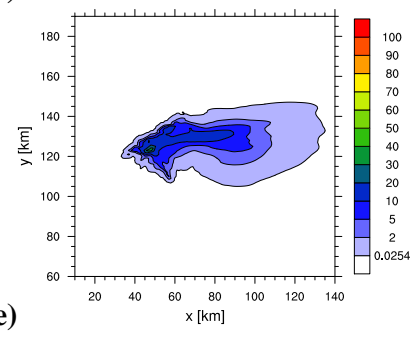

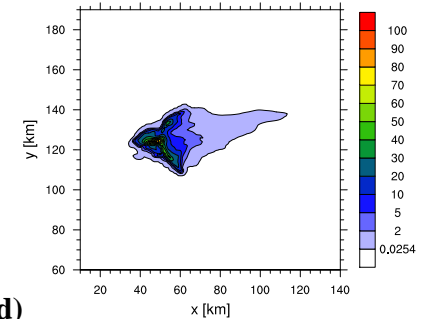

(d)

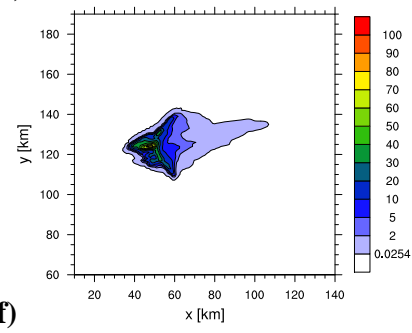

Fig. 10. As in Fig. 4 except for the low relative humidity scenario.

in the bulk lowRH simulations for all aerosol perturbations. In other words, the models still disagree on the sign of the aerosol-induced effect on precipitation from deep convective clouds. It should be noted that the change in precipitation from the "Clean" to "Semi-Polluted" case is not statistically significant for $\alpha=0.01$. Table 2 shows the domain-averaged cumulative precipitation at the end of the simulations and the relative changes due to increased aerosol loading. Moreover, Figs. 10 and 11 show the cumulative precipitation at 2 and $4 \mathrm{~h}$ into the simulations, respectively. Comparing with Figs. 4 and 5, we see that the main result of decreasing the $\mathrm{RH}$ is to reduce the precipitation in the regions of intense rainfall (i.e., Figs. 10 and 11 show smaller areas in with the precipitation is greater than $70 \mathrm{~mm}$ for the bin model and greater than 40 for the bulk model, compared with Figs. 4 and 5).

Figure 12 demonstrates that the rain water content (dashed) is initially suppressed, as expected for increased $\mathrm{CCN}$ number concentrations for the bin microphysics simulations. As time progresses, the rain water content is always highest in the "Clean" case (black) for the bin microphysics simulations like in the highRH scenario. Since the rain water content for the "Semi-Polluted" and "Polluted" scenarios never exceeds that for the "Clean" case, it is physically not possible for the domain-averaged cumulative precipitation for the perturbed cases to exceed that of the "Clean" base case. 

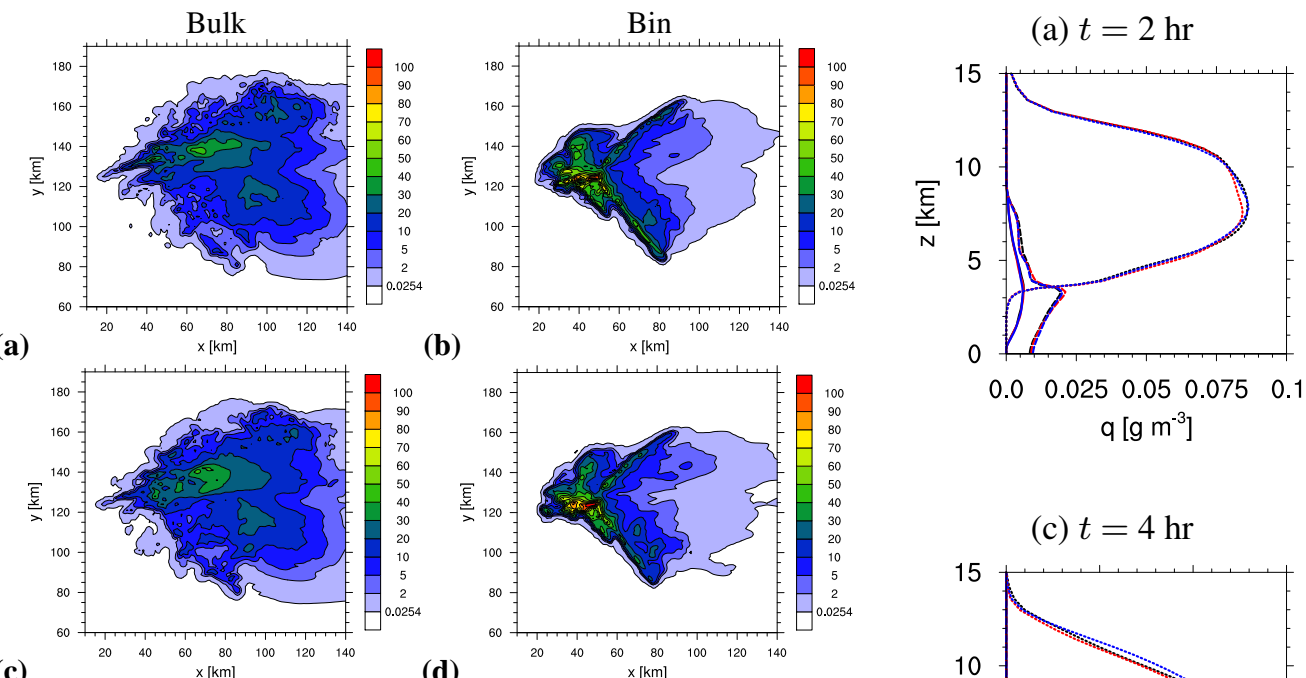

(a) $t=2 \mathrm{hr}$

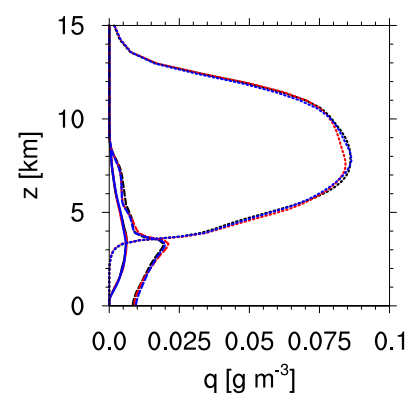

(c) $t=4 \mathrm{hr}$

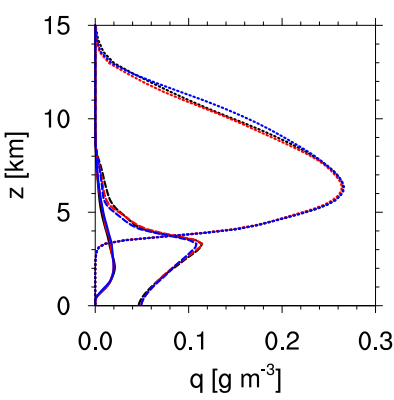

(e) $t=6 \mathrm{hr}$

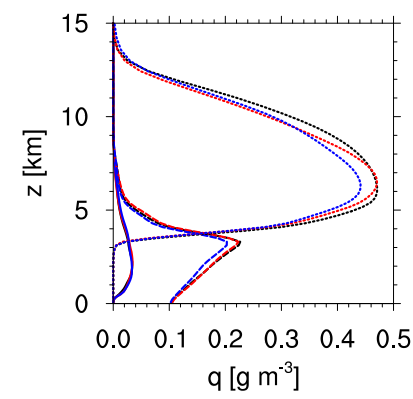

(b) $t=2 \mathrm{hr}$

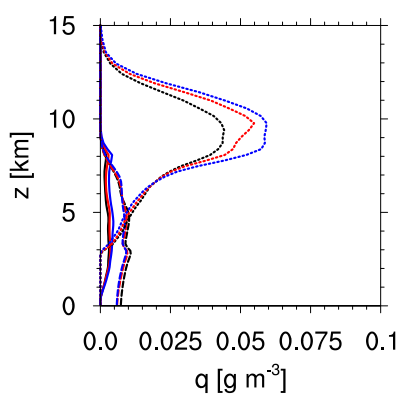

(d) $t=4 \mathrm{hr}$

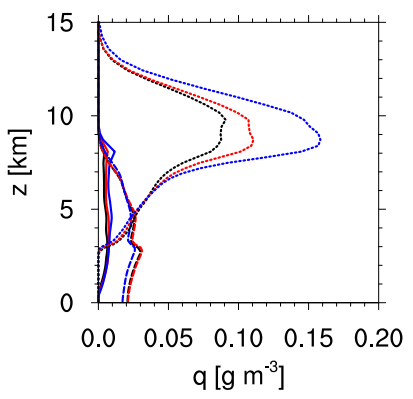

(f) $t=6 \mathrm{hr}$

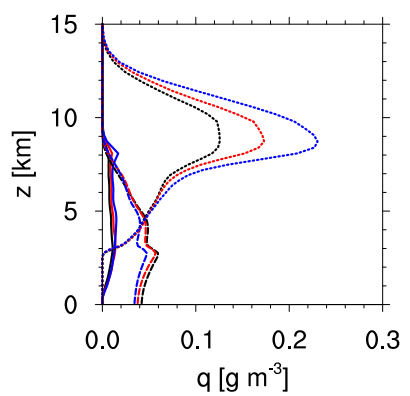

Fig. 11. As in Fig. 10 except after $4 \mathrm{~h}$ of simulation time.

Following the same line of logic as for the highRH cases, to analyze the dynamical feedback that occurs when the $\mathrm{CCN}$ number concentration is perturbed, we show the mean vertical velocity for each polluted scenario and the changes therein due to such perturbations in Fig. 13. Here it is shown that $w$ tends to decrease as the $\mathrm{CCN}$ number concentration increases for simulations performed with both the bin and bulk microphysics schemes under relatively low RH conditions, unlike that for the highRH cases. In fact, the bulk simulations show a decrease in $w$ of 5 to $20 \%$ while the bin simulations suggest a decrease up to $15 \%$ within the cloudy part of the convective core (Fig. 13b). This elicits the question: Why is convection suppressed for all aerosol perturbation simulations while the precipitation response differs between the bin and bulk simulations?

The key to answering this question is to note first that the mean profile of $w$ is for that of the convective core itself. Hence, details of the changes in evaporation, sedimentation, etc., as a result of increasing the $\mathrm{CCN}$ number concentration may not be included in such a figure. Therefore, we show in Fig. $13 \mathrm{c}$ and $\mathrm{d}$ the domain-averaged latent heating profiles for the lowRH simulations. For the bulk simulations under low RH conditions, there is no significant change in latent heating due to increases in $\mathrm{CCN}$ number concentration. However, there is a slight increase in $q_{\mathrm{t}}$, thus resulting in a decrease in $B$ and consequently, $w$, as well. Similar

Fig. 12. Same as Fig. 6 except for the lowRH simulations. Simulation time is shown in the subcaptions.

to that for the highRH cases, the bin microphysics scheme predicts more significant changes in latent heating due to changes in aerosol loading. From Figs. $7 d$ and $13 d$ we see that although the sign of the change in heating rates for increased CCN number concentration is identical for both RH scenarios, the magnitude is not. In fact, the increase in cooling due to an increase in the $\mathrm{CCN}$ number concentration is more for the lowRH scenario (since lower RH implies more evaporation/sublimation) for both the "Semi-Polluted" and "Polluted" cases. In other words, evaporation/sublimation is enhanced in the bin model results for a decrease in $\mathrm{RH}$ as one may expect. The warming due to phase changes occurs predominantly within the convective core itself, while the cooling occurs at the cloud boundaries and below cloud (from precipitation evaporation/sublimation). It is this increase in 


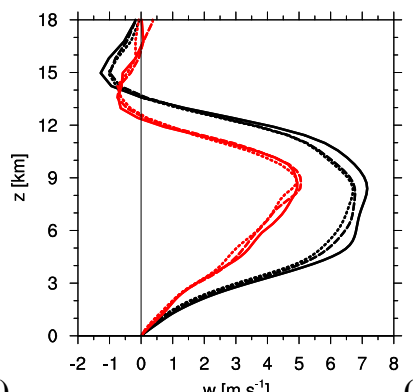

(a)

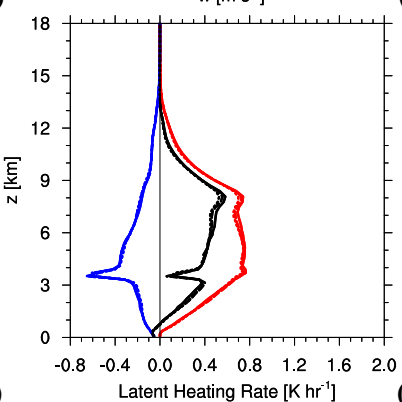

(c)

Latent Heating Rate $\left[\mathrm{K} \mathrm{hr}^{-1}\right]$

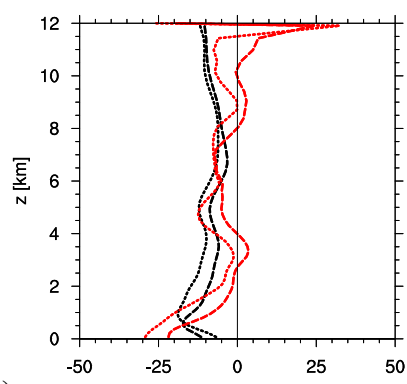

(b)

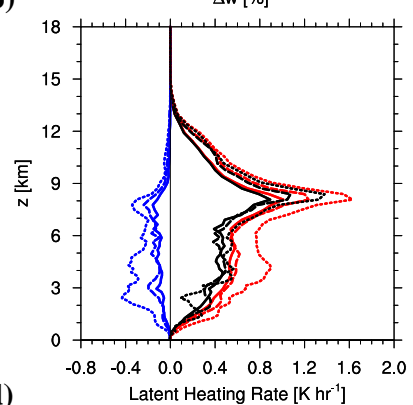

(a)
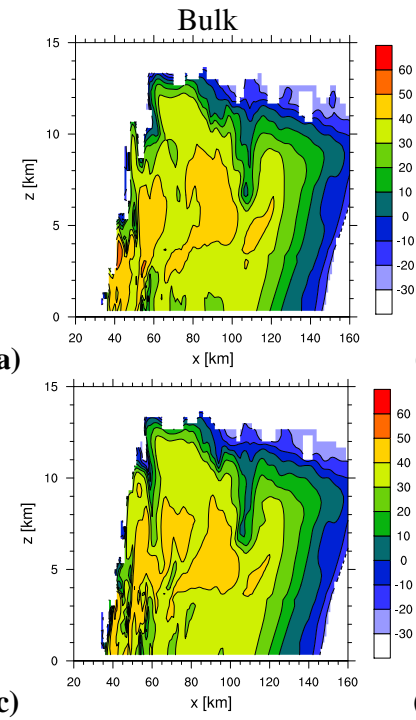

(c)

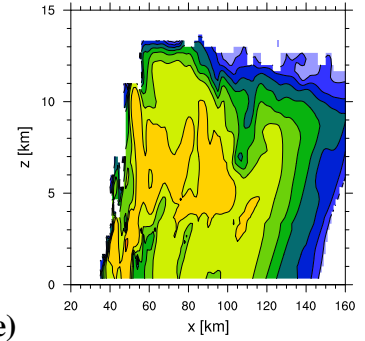

(b)

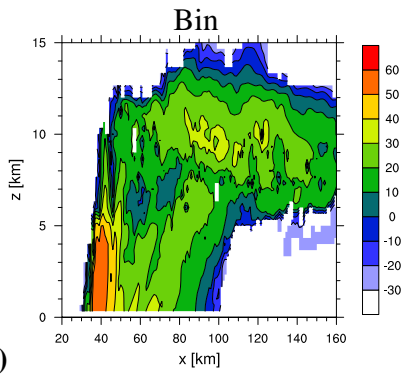

Fig. 13. As in Fig. 7 except for the lowRH simulations.

evaporation/sublimation aloft (Fig. 13) that ultimately leads to a reduction in the domain averaged precipitation (Fig. 9) for the lowRH cases using bin microphysics. As mentioned above for bin simulations for the highRH scenario, there exists a competition between evaporation and sedimentation that ultimately controls the sign of the aerosol-induced effect on the precipitation resulting from deep convection. By reducing $q_{\mathrm{v}}$ in the lowRH scenario, we essentially reduce the total condensed water mass in the cloud itself. Hence, all else being equal, particles in the "Clean" case will be smaller under the relatively low RH conditions in comparison to that of higher RH. The same goes for the "Semi-Polluted" and "Polluted" cases. As a result, the sedimentation timescale of the particles aloft is increased while the evaporation timescale is reduced for a decrease in $\mathrm{RH}$. As a result, for even the smallest increase in the $\mathrm{CCN}$ number concentration shown (i.e., doubling from 100 to $200 \mathrm{~cm}^{-3}$ ), the evaporative effect outweighs the sedimentation rate and so consequently, less condensed water is converted to rain water and thus less precipitation is observed at the surface. In fact, the increase in evaporation actually further decreases the sedimentation rate of cloud particles.

The fact that the overall effect of an increase in the CCN number concentration on the cumulative precipitation is inherently tied to the intricate balance between sedimentation and evaporation/sublimation time scales is further corroborated (as was the case for the highRH simulations) by looking at the radar reflectivity factor $(Z$, Fig. 14). As described above in Eq. (18), an increase in $q_{\mathrm{t}}$ leads to an increase in $Z$ if and only if the particles remain the same size (i.e., more numerous particles of the same size). On the other hand,

\section{(e)}

Fig. 14. As in Fig. 8 except for the lowRH scenario

as mentioned above, an increase in $q_{\mathrm{t}}$ with no increase in $Z$ signifies that the particles must be smaller, and thus sedimentation is reduced. This is precisely what the bin model simulations suggest (Fig. 14b, d, and f). Clearly there is no significant change in $Z$ due to increased aerosol loading while Figs. $6 \mathrm{~b}, \mathrm{~d}$, and $\mathrm{f}$ suggest that $q_{\mathrm{t}}$ is increased. The changes in particle size are harder to determine for the bulk simulations, especially between the "Clean" and "Semi-Polluted" cases. This should be expected given the smaller relative change in precipitation for increased CCN number concentration compared with the bin model (Table 2).

\subsection{IN effects on deep convective clouds}

Here we test the sensitivity of each microphysics scheme to the IN number concentration. In order to determine the significance of modifying the ambient IN number concentration we double the number of IN predicted at the ambient temperature in each model. This may prove to be important because, as shown previously by Barahona and Nenes (2009) the number of available IN acts to control whether the predominant freezing mechanism is homogeneous or heterogenous. In other words, as the IN number concentration increases, physically the number of droplets that freeze and consequently grow via vapor diffusion should increase at 
Table 3. Domain-averaged cumulative precipitation at the completion of the simulations performed including potential IN effects, $t=6 \mathrm{~h}$.

\begin{tabular}{lccccc}
\hline Micro. & RH Profile & “Clean” Precip. & "Semi-Polluted” Precip. & "IN-Polluted" Precip. & $\Delta$ Precip. \\
\hline Bin & highRH & $4.42 \mathrm{~mm}$ & $3.94 \mathrm{~mm}$ & $3.83 \mathrm{~mm}$ & $-2.82 \%(-13.4 \%)$ \\
Bulk & highRH & $7.94 \mathrm{~mm}$ & $8.16 \mathrm{~mm}$ & $8.13 \mathrm{~mm}$ & $-0.44 \%(2.38 \%)$ \\
Bin & lowRH & $2.39 \mathrm{~mm}$ & $2.25 \mathrm{~mm}$ & $2.17 \mathrm{~mm}$ & $-3.67 \%(-9.2 \%)$ \\
Bulk & lowRH & $4.59 \mathrm{~mm}$ & $4.69 \mathrm{~mm}$ & $4.77 \mathrm{~mm}$ & $1.65 \%(3.91 \%)$ \\
\hline
\end{tabular}

* $\Delta$ Precip. is computed for the "IN-Polluted" case compared with that of the "Semi-Polluted" case, demonstrating the impact of changes in the IN number concentration. $\Delta$ Precip. between the "IN-Polluted" and "Clean" cases is given in parentheses.

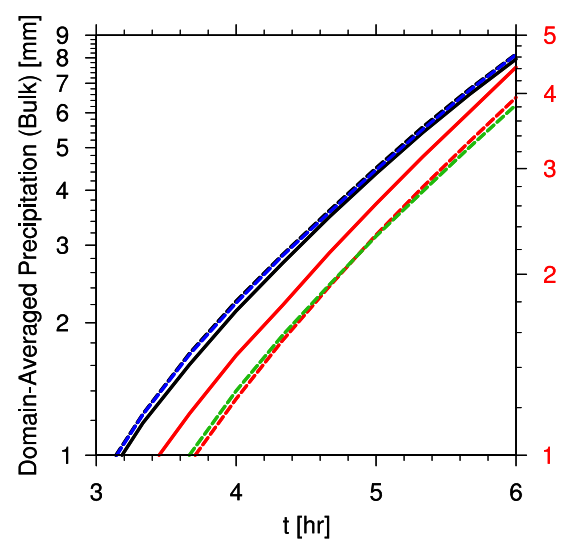

Fig. 15. Domain-averaged cumulative precipitation for the highRH simulations using (a) bulk and (b) bin microphysics. CCN/IN effects are shown for the "Clean" (solid), "Semi-Polluted" (dashed), and "IN-Polluted" (dotted) scenarios. Note the difference in the $y$ axis scale between (a) and (b). The bulk and bin results have been separated here for clarity.

warmer temperatures, thus depleting the ambient vapor surplus and limiting the number of droplets that freeze via homogeneous freezing at much colder temperatures.

Figure 15 illustrates the effect of an increase in the IN number concentration for both microphysics models in conjunction with an increase in the $\mathrm{CCN}$ number concentration for the highRH scenario (the results for a reduction in $\mathrm{RH}$ are qualitatively consistent with that of the highRH scenario and are thus not shown). Note that the $y$-axes are logarithmically spaced to accentuate the small differences in precipitation due to perturbing the IN number concentration. The sign of the resulting influence on the domain-averaged cumulative precipitation from an increase in IN number concentration agrees for the two microphysics models, i.e., the both models suggest that the precipitation will decrease further when the IN number concentration is increased. Table 3 shows the relative change in precipitation as a result of the aforementioned changes in the IN number concentration. We should note that the change in the domain-averaged cumulative precipitation from the "Semi-Polluted" to the "IN-Polluted" case is not

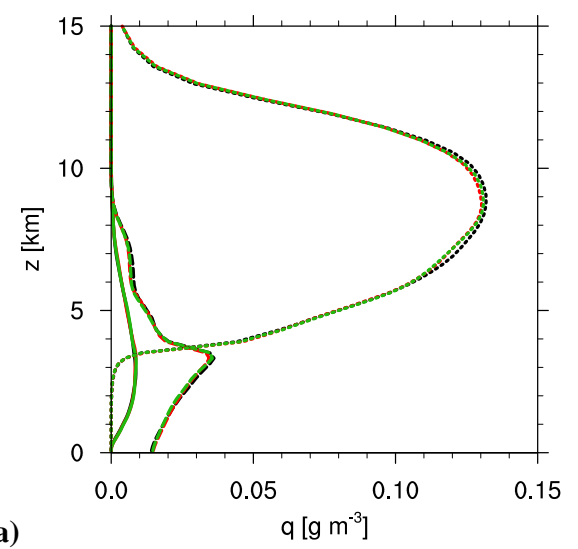

(a)

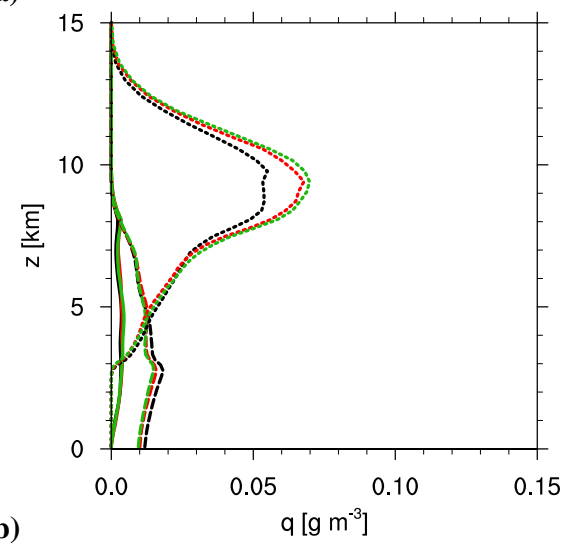

Fig. 16. Domain-averaged cloud (solid), rain (dashed), and ice (dotted) water contents for the bulk (left) and bin (right) simulations after $2 \mathrm{~h}$ of simulation time. The aerosol sensitivity is shown for the "Clean" (black), "Semi-Polluted" (red), and "IN-Polluted" (green) scenarios.

statistically significant, even if we increase the significance level such that $\alpha=0.10$.

The decrease in the domain-averaged cumulative precipitation for the simulations with bin microphysics is explained following the same line of reasoning as that which was used above for the decrease observed for an increase in the CCN number concentration in the bin model. From Fig. 16, both models suggest a slight increase in $q_{\mathrm{i}}$ due to an increase in 


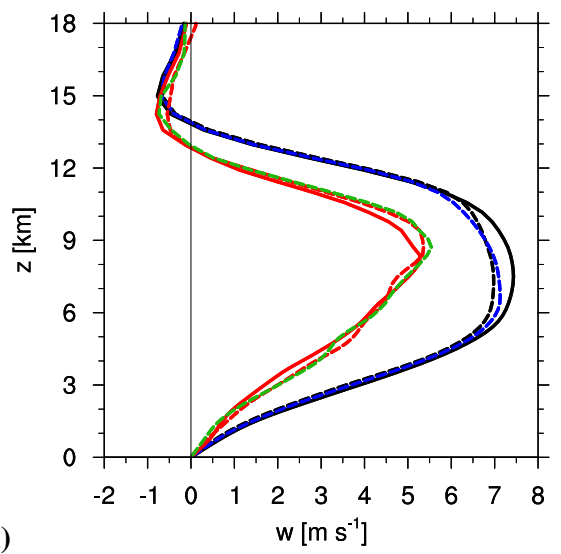

(a)

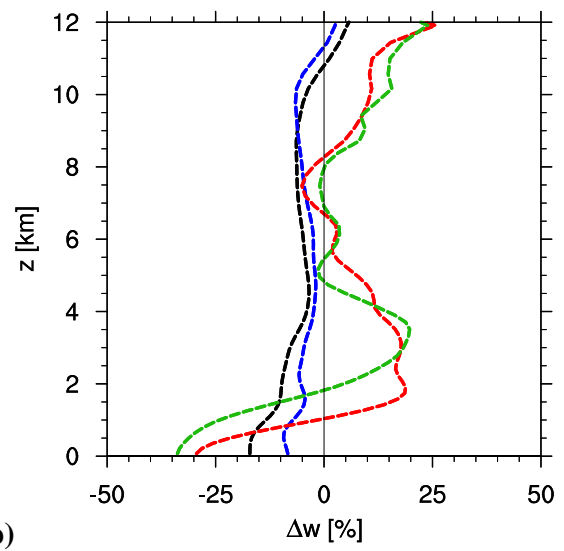

Fig. 17. (a) Average of the vertical velocity profile within the convective core and (b) the change in the mean vertical velocity due to changes in $\mathrm{CCN}$ number concentration. The convective core is defined to contain the columns in which the mean vertical velocity is more than $1 \mathrm{~m} \mathrm{~s}^{-1}$. Bulk (black) and bin (red) are displayed on the same graph. The differences are performed for the "Semi-Polluted" (dashed) and "IN-Polluted" (dashed, green and blue for bin and bulk simulations, respectively) cases relative to the "Clean" (solid) case. The vertical axis is different so as to highlight the differences within the cloud itself and because the relative differences at cloud top and above are much larger than those within the cloud. Simulation time is shown in the subcaptions.

the ambient IN number concentration. However, by increasing the IN number concentration, we also increase $N_{\mathrm{i}}$ such that the sizes of the ice particles are now smaller on average and consequently, the particles tend to fall more slowly. The result is a slight decrease in the domain-averaged cumulative precipitation. We see that the precipitation cannot increase beyond that of the "Semi-Polluted" case because the rain water content is always at most about equal between the two cases (Fig. 16).

Dynamically, the response to an increase in the IN number concentration is shown to be quite small in comparison to the changes that arise due to increasing the $\mathrm{CCN}$ number concentration alone (Fig. 17).

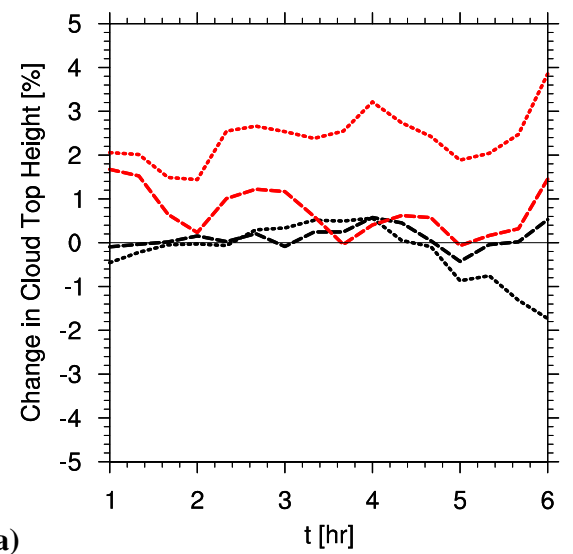

(a)

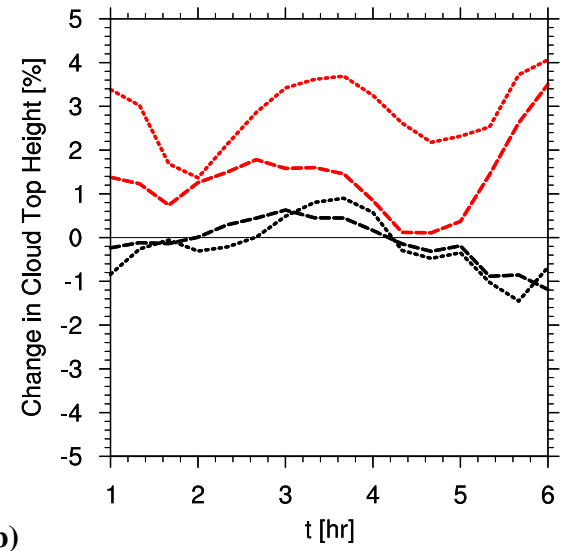

Fig. 18. The change in mean cloud top height is depicted for the "Semi-Polluted" (dashed) and "Polluted" (dotted) scenarios relative to the "Clean" case using both the bulk (black) and bin (red) microphysics schemes for the (a) highRH and (b) lowRH scenarios.

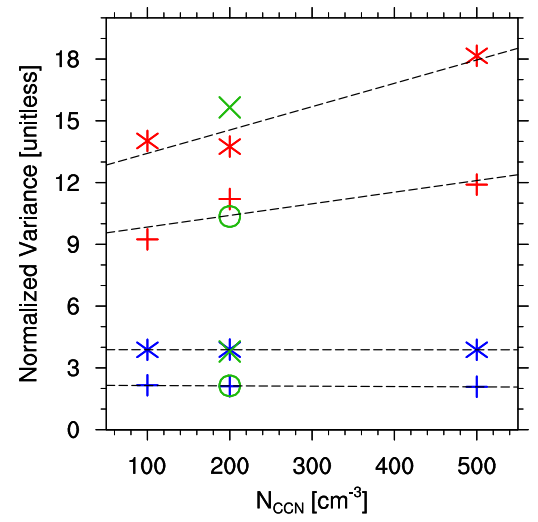

Fig. 19. Variance in the normalized cumulative precipitation for all simulations shown as a function of $N_{\mathrm{CCN}}$. Both bin (red) and bulk (blue) simulations are shown. The IN sensitivity runs are also shown (green). The lowRH scenario (stars) and highRH scenarios are depicted (pluses). The dashed lines are drawn to show any potential trend in the variance with changes in aerosol loading. 


\subsection{Cloud top height effects}

To shed light on the potential impact of cloud top height in controlling the amount of precipitation that results for a perturbed deep convective cloud (Stevens and Feingold, 2009), we show the change in cloud top height in Fig. 18 for the "Semi-Polluted" and "Polluted" cases relative to that of the "Clean" case for both microphysical schemes. There is a rather consistent increase in cloud top height for the simulations performed using the bin microphysics scheme whereas the bulk scheme shows a change in cloud top height of less than $0.5 \%$, up or down, for most of the simulations, regardless of the chose RH scenario. This slight increase in the cloud top height from the bin model is due to the fact that the smaller particles in the polluted cases are more likely to stay lofted and be lofted higher without a change in $w$. However, the reason for a modest change in the cloud top height, as suggested might occur by Stevens and Feingold (2009), is because the clouds in question in this study are very deep, extending from the lifted condensation level (LCL) to the tropopause. Without a significant increase in vertical velocity near the equilibrium level, i.e., just below the tropopause, allowing moisture to punch higher into the lower stratosphere, it is very difficult to increase the height of such a cloud and hence increase the amount of condensed water mass due solely to adiabatic lifting of moist parcels.

\subsection{Precipitation intensity}

Although it was shown above that the overall result of an increase in the $\mathrm{CCN}$ number concentration is to reduce the domain-averaged cumulative precipitation based on bin microphysics (while the bulk model suggest otherwise), this does not mean that the intensity of the rainfall also decreases. To determine the effect of increased aerosol loading on rainfall intensity, we look at the variance of the normalized cumulative precipitation. In other words, the domain-average of the cumulative precipitation is normalized and the variance of the resulting nondimensional precipitation values is computed and shown in Fig. 19 for all simulations. The dashed lines are shown to demonstrate any potential tendency. A larger normalized variance corresponds to more intense rainfall. Since these are domain-averages, there is a slight increase from the highRH to lowRH scenario as a result of a larger area in which there is no precipitation in the drier case. However, comparing the suite of simulations performed for the highRH scenario, Fig. 19 suggests that there is little change in the intensity of the rainfall using the bulk scheme, while on the other hand, the bin results suggest an increase in intensity with increasing $\mathrm{CCN}$ number concentration. This result is corroborated in Fig. $8 \mathrm{~b}$, d, and $\mathrm{f}$ we see that the area of highest $Z(Z>60 \mathrm{dBZ})$ tends to increase with increased aerosol loading, while the region of moderate $Z(40 \mathrm{dBZ}<Z<60 \mathrm{dBZ})$ tends to decrease. Moreover, Fig. 8 $\mathrm{a}, \mathrm{c}$, and e shows that there is essentially no change in the size of the area of higher $Z$ (i.e., $Z>30$ ) and consequently, the trendline in Fig. 19 has a slope of nearly 0.

When the RH is reduced, Fig. 19 suggests no change in the rainfall intensity using the bulk microphysics scheme and the change in intensity using bin microphysics appears to not be monotonic. This change is also reflected in the radar reflectivity contour plots for lowRH (Fig. 14). Figure 14a, $\mathrm{c}$, and e shows that there is little change (as was the case for highRH) in the width of the swath of heavier precipitation (or higher reflectivity, $Z>30 \mathrm{dBZ}$ ). On the other hand, for the bin microphysics simulations, Fig. 14b, d show little change in the extent of the region of higher reflectivity for an increase in $N_{\mathrm{CCN}}$ from 100 to $200 \mathrm{~cm}^{-3}$ while a further increase in the CCN number concentration reduces the size of the area of higher reflectivity (especially near the surface) but a small are of $Z>60 \mathrm{dBZ}$ appears, giving evidence of more intense rainfall. One possible explanation for this non-monotonic effect under low RH conditions could be that a slight increase in the CCN number concentration reduces the size of the cloud particles and thus decreases the evaporation/sublimation time scale, prohibiting enhanced rainfall near the core. However, a further increase in the CCN number concentration, although also decreasing the size of the cloud particles, may also act to enhance riming due to the increase in the number of cloud particles. The enhanced riming near the core could then lead to larger particles with higher reflectivity and ultimately more intense rainfall near the center.

\section{Conclusions}

We have presented a high-resolution detailed CRM study (via the WRF model) of the potential effect(s) of aerosol perturbations on the development of deep convective clouds. The study incorporates two different microphysics schemes:

1. Bin Microphysics - a mixed-phase bin microphysics scheme (see Sect. 3.1), based on Tzivion et al. (1987, 1989), Stevens et al. (1996), and Reisin et al. (1996), coupled to WRF for very detailed microphysics calculations.

2. Modified Bulk Microphysics - the twomoment six-class bulk microphysics scheme of Morrison et al. (2005) and Morrison and Pinto (2005), modified to include a physically-based activation scheme based upon the explicit calculation of the activation of a bin-resolved aerosol population.

We test the sensitivity of the domain-averaged cumulative precipitation and potential convective invigoration as seen by changes in updraft velocity within the convective core to changes in the ambient aerosol concentration by performing simulations with an increase in the CCN number concentration, as well as a suite of cases in which both the CCN and IN 
number concentrations are increased. The simulated results are compared to the predictions for the base case (i.e., the "Clean" scenario). The dependence of the aerosol-induced effect on the ambient RH is also analyzed.

Under relatively moist ambient conditions, it is shown that an increase in the CCN number concentration elicits different responses from the two microphysics schemes; the bulk scheme suggests a slight increase while the bin scheme suggests a decrease in the domain-averaged cumulative precipitation. The increase in the $\mathrm{CCN}$ number concentration leads to an increase in $q_{\mathrm{i}}$ and consequently, $q_{\mathrm{t}}$ aloft regardless of the microphysics scheme employed. However, the relative increase is much larger for the simulations performed with bulk microphysics. This much larger increase is shown to be a result of more numerous smaller cloud particles that ultimately have a slower sedimentation velocity, leading to a reduction in the precipitation at the surface. It is suggested that the bin model ought to be superior to the bulk model for such high-resolution CRM simulations due to the difference in one key underlying assumption of the two models: the bulk model incorporates a saturation adjustment scheme (i.e., the saturation ratio is assumed to be 1 after the microphysics calculations are performed). For high-resolution simulations with short time steps, as is the case in the present study, the condensational growth timescale may be longer than the time step (Chuang et al., 1997) and thus the grid box may remain supersaturation at the end of a time step. This assumption may lead to an over-prediction of the cloud mass and thus precipitation.

It is also shown that a slight enhancement in updraft velocity occurs for increased aerosol loading using the bin microphysics scheme, while the bulk scheme suggests a slight suppression. The increase in $w$ for the bin simulations aids in keeping cloud particles lofted in the cloud and increasing the sedimentation timescale. On the other hand, the reduction in $w$ allows for the sedimentation timescale to be reduced, thus allowing the particles to reach the surface faster and increase precipitation.

Moreover, when the ambient RH is reduced, it is shown that the two microphysics models still disagree on the sign of the aerosol-induced effect(s) on precipitation; the bin model suggests a significant decrease while the bulk model suggests an increase. As was the case for increasing the CCN number concentration from the "Clean" to "Polluted" scenario under relatively high $\mathrm{RH}$ using the bin microphysics scheme, the competition between evaporation/sublimation and sedimentation dominates the sign of the aerosol-induced effect. Here, under dryer conditions, evaporation/sublimation occurs on even a shorter timescale and as a result dominates the sedimentation for all aerosol perturbations. Thus, a decrease in the rain water content and ultimately precipitation is observed. On the contrary, the bulk model suggests a larger decrease in $w$ for an increase in the CCN number concentration which, even though the cloud particles are smaller in the perturbed cases, allows the cloud particles to sediment at a rate at least as large as in the "Clean" case and ultimately increase precipitation.

Changes in the aerosol loading may not necessarily provide particles that act solely as CCN. Some particles are good IN, and thus it is prudent to analyze and understand any and all potential impacts of the IN population on the development of deep convective clouds and the resulting precipitation amount and pattern, at least in terms of testing the model's sensitivity to the predicted IN number concentration. The results presented herein suggest that the influence of additional IN on the domain-averaged cumulative precipitation is not statistically significant. Both models suggest a slight decrease in precipitation regardless of the RH scenario, and this is related to an increase in $N_{\mathrm{i}}$ and thus a decrease in the ice crystal sizes for an increase in the IN number concentration.

Our results demonstrate that any and all changes in the precipitation at the surface are dominated by changes in the mass of condensed water and the competition that exists between evaporation/sublimation and sedimentation and are not related to changes in cloud top height (since it is shown, especially for the simulations performed with bin microphysics, that the cloud top height increases slightly, but the precipitation decreases). For shallow convection, Stevens and Feingold (2009) hypothesized that an increase in cloud top evaporation/sublimation due to smaller particles sizes would act to moisten and cool the layer above the cloud and help to deepen the cloud itself. Although we find an increase in evaporation/sublimation near the top of the clouds in this study, the result is not to extensively deepen the clouds since the tops are limited in their height by the tropopause. Thus, any increase/decrease in precipitation cannot come from deepening the deep convective cloud, as could be the case for a shallower convective cloud.

Lastly, we present evidence for an increase in rainfall intensity due to an increase in the $\mathrm{CCN}$ number concentration. Although the bulk model exhibits no trend in precipitation variance with increased aerosol loading, the bin model shows a clear increase in the precipitation variance as the $\mathrm{CCN}$ number concentration increases, especially in a moist environment. We relate the increase in rainfall intensity in the presence of a decrease in domain-averaged cumulative precipitation to an increase in riming within the area of significant rainfall (leading to higher reflectivity) and a decrease in precipitation in the surrounding areas due to decreased sedimentation (caused by reducing the size of the particles for an increase in the aerosol loading).

The present work could be extended to provide a more detailed description of the $\mathrm{CCN}$ and IN populations. Recently, work has been done to relate the number of active IN to the number of CCN particles of considerable size (DeMott et al., 2010). Incorporating this approach into the bin microphysics model would allow one to tie together increases in the $\mathrm{CCN}$ and IN number concentrations. Furthermore, a detailed comparison with satellite observed cloud water 
masses, both liquid and ice, would be beneficial in understanding both how CCN and IN particles can and do modify deep convective clouds. Ideally, an ambient vertical profile of aerosol concentration and type collocated with observations of bulk cloud properties and precipitation can build upon the current study.

Acknowledgements. This work was supported by the Office of Naval Research grant N00014-10-1-0200. We thank Jerry Harrington, Hugh Morrison, Adrian Hill, and Graham Feingold for helpful discussions. Computations were carried out on the CITerra Dell Cluster of the Geological and Planetary Sciences Division at Caltech.

Edited by: A. Nenes

\section{References}

Ackerman, A. S., Kirkpatrick, M. P., Stevens, D. E., and Toon, O. B.: The impact of humidity above stratiform clouds on indirect aerosol climate forcing, Nature, 432, 1014-1017, 2004.

Albrecht, B.: Aerosols, Cloud Microphysics, and Fractional Cloudiness, Science, 245, 1227-1230, doi:10.1126/science.245.4923.1227, 1989.

Andreae, M. O.: Correlation between cloud condensation nuclei concentration and aerosol optical thickness in remote and polluted regions, Atmos. Chem. Phys., 9, 543-556, doi:10.5194/acp-9-543-2009, 2009.

Andrejczuk, M. O., Rosenfeld, D., Artaxo, P., Costa, A. A., Frank, G. P., Longo, K. M., and Silva-Dias, M. A. F.: Smoking rain clouds over the Amazon, Science, 303, 1337-1342, 2004.

Barahona, D. and Nenes, A.: Parameterizing the competition between homogeneous and heterogeneous freezing in cirrus cloud formation - monodisperse ice nuclei, Atmos. Chem. Phys., 9, 369-381, doi:10.5194/acp-9-369-2009, 2009.

Bigg, E. K.: The formation of atmospheric ice crystals by the freezing of droplets, Q. J. Roy. Meteorol. Soc., 79, 510-519, 1953.

Chuang, P. Y., Charlson, R. J., and Seinfeld, J. H.: Kinetic limitations on droplet formation in clouds, Nature, 390, 94-96, 1997.

Clark, T. L.: A Study in Cloud Phase Parameterization Using The Gamma Function, J. Atmos. Sci., 31, 142-155, 1974.

Cooper, W. A.: Ice initiation in natural clouds, Meteor. Monograph, 21, 29-32, 1986.

DeMott, P. J., Sassen, K., Poellot, M. R., Baumgardner, D., Rogers, D. C., Brooks, S. D., Prenni, A. J., and Kreidenweis, S. M.: African dust aerosols as atmospheric ice nuclei, Geophys. Res. Lett., 30, 1732-1735, doi:10.1029/2003GL017410, 2003.

DeMott, P. J., Prenni, A. J., Liu, X., Kreidenweis, S. M., Petters, M. D., Twohy, C. H., Richardson, M. S., Eidhammer, T., and Rogers, D. C.: Predicting Global Atmospheric Ice Nuclei Distributions and their Impacts on Climate, Proc. Natl. Acad. Sci. USA, 107, 11217-11222, doi:10.1073/pnas.0910818107, 2010.

Fan, J., Yuan, T., Comstock, J. M., Ghan, S., Khain, A. ., Leung, L. R., Li, Z., Martins, V. J., and Ovchinnikov, M.: Dominant role by vertical wind shear in regulating aerosol effects on deep convective clouds, J. Geophys. Res., 114, D22206, doi:10.1029/2009JD012352, 2009.

Feingold, G., Tzivion, S., and Levin, Z.: Evolution of raindrop spectra. Part I: solution to the stochastic collection/breakup equation using the method of moments, J. Atmos. Sci., 45, 3387-3399, 1988.

Fletcher, N. H.: The Physics of Rainclouds, Cambridge University Press, New York, NY, USA, 386 pp., 1962.

Freud, E., Rosenfeld, D., Andreae, M. O., Costa, A. A., and Artaxo, P.: Robust relations between $\mathrm{CCN}$ and the vertical evolution of cloud drop size distribution in deep convective clouds, Atmos. Chem. Phys., 8, 1661-1675, doi:10.5194/acp-8-1661-2008, 2008.

Geresdi, I. and Rasmussen, R. M.: Freezing drizzle formation in stably stratified layer clouds. Part II: T role of giant nuclei and aerosol particle size distribution and solubility, J. Atmos. Sci., 62, 2037-2057, 2005.

Harrington, J. Y., Feingold, G., and Cotton, W. R.: Radiative Impacts on the Growth of a Population of Drops within Simulated Summertime Arctic Stratus, J. Atmos. Sci., 57, 766-785, 2000.

Heymsfield, A. J. and Kajikawa, M.: An Improved Approach to Calculating Terminal Velocities of Plate-like Crystals and Graupel, J. Atmos. Sci., 44, 1088-1099, 1987.

Hill, A. A., Dobbie, S., and Yin, Y.: The impact of aerosols on non-precipitating marine stratocumulus. Model description and prediction of the indirect effect, Q. J. Roy. Meteorol. Soc., 134, 1143-1154, doi:10.1002/qj.278, 2008.

Hill, A. A., Feingold, G., and Jiang, H.: The influence of entrainment and mixing assumption on aerosol-cloud interactions in marine stratocumulus, J. Atmos. Sci., 66, 1450-1464, 2009.

Houze, R. A.: Cloud Dynamics, vol. 53 of International Geophysics Series, Academic Press, Inc., San Diego, California, USA, 1993.

IPCC: Summary for Policymakers, in: Climate Change 2007: The Physical Science Basis. Contribution of Working Group I to the Fourth Assessment Report of the Intergovernmental Panel on Climate Change, edited by: Solomon, S., Qin, D., Manning, M., Chen, Z., Marquis, M., Averyt, K. B., Tignor, M., and Miller, H. L., Cambridge University Press, Cambridge, United Kingdom and New York, NY, USA, 996 pp., 2007.

Khain, A. and Lynn, B.: Simulation of a supercell storm in clean and dirty atmosphere using weather research and forecasting model with spectral bin microphysics, J. Geophys. Res., 114, D19209, doi:10.1029/2009JD011827, 2009.

Khain, A. and Pokrovsky, A.: Simulation of effects of atmospheric aerosols on deep turbulent convective clouds using a spectral microphysics mixed-phase cumulus cloud model. Part II: sensitivity study, J. Atmos. Sci., 61, 2983-3001, 2004.

Khain, A., Ovtchinnikov, M., Pinsky, M., Pokrovsky, A., and Krugliak, H.: Notes on the state-of-the-art numerical modeling of cloud microphysics, Atmos. Res., 55, 159-224, 2000.

Khain, A., Pokrovsky, A., Pinsky, M., Seifert, A., and Phillips, V.: Simulation of effects of atmospheric aerosols on deep turbulent convective clouds using a spectral microphysics mixed-phase cumulus cloud model. Part I: Model description and possible applications, J. Atmos. Sci., 161, 2963-2982, 2004.

Khain, A., BenMoshe, N., and Pokrovsky, A.: Factors Determining the Impact of Aerosols on Surface Precipitation from Clouds: An Attempt at Classification, J. Atmos. Sci., 65, 1721-1748, 2008.

Khain, A., Rosenfeld, D., Pokrovsky, A., Blahak, U., and Ryzhkov, A.: The role of $\mathrm{CCN}$ in precipitation and hail in a mid-latitude storm as seen in simulation using a spectral (bin) microphysics model in a 2D dynamic frame, Atmos. Res., 99, 129-146, 2011.

Kogan, Y. L.: The simulation of a convective cloud in a 3D model 
with explicit microphysics. Part I: Model description and sensitivity experiments, J. Atmos. Sci., 48, 1160-1189, 1991.

Koren, I., Kaufman, Y. J., Rosenfeld, D., Remer, L. A., and Rudich, Y.: Aerosol invigoration and restructuring of Atlantic convective clouds, Geophys. Res. Lett., 32, L14828, doi:10.1029/2005GL023187, 2005.

Koren, I., Remer, L. A., Altaratz, O., Martins, J. V., and Davidi, A.: Aerosol-induced changes of convective cloud anvils produce strong climate warming, Atmos. Chem. Phys., 10, 5001-5010, doi:10.5194/acp-10-5001-2010, 2010.

Lee, S. S.: Dependence of aerosol-precipitation interactions on humidity in a multiple-cloud system, Atmos. Chem. Phys., 11, 2179-2196, doi:10.5194/acp-11-2179-2011, 2011.

Lee, S. S. and Feingold, G.: Precipitating cloud-system response to aerosol perturbations, Geophys. Res. Lett., 37, L23806, doi:10.1029/2010GL045596, 2010.

Locatelli, J. D. and Hobbs, P. V.: Fall Speeds and Masses of Solid Precipitation Particles, J. Geophys. Res., 79, 2185-2197, 1974.

Long, A. B.: Solutions to the droplet collection equation for polynomial kernels, J. Atmos. Sci., 31, 1040-1052, 1974.

Lu, M. and Seinfeld, J. H.: Effect of aerosol number concentration on cloud droplet dispersion: A large-eddy simulation study and implications for aerosol indirect forcing, J. Geophys. Res., 111, D12304, doi:10.1029/2005JD006419, 2006.

Meyers, M. P., DeMott, P. J., and Cotton, W. R.: New primary ice nucleation parameterization in an explicit model, J. Appl. Meteor., 31, 708-721, 1992.

Morales, R. and Nenes, A.: Characteristic Updrafts for Computing Distribution-Averaged Cloud Droplet Number and Stratocumulus Cloud Properties, Geophys. Res. Lett., 115, D18220, doi:10.1029/2009JD013233, 2010.

Morrison, H. and Pinto, J. O.: Mesoscale Modeling of Springtime Arctic Mixed-Phase Stratiform Clouds Using a New TwoMoment Bulk Microphysics Scheme, J. Atmos. Sci., 62, 36833704, 2005.

Morrison, H., Curry, J. A., and Khvorostyanov, V. I.: A new doublemoment microphysics parameterization for application in cloud and climate models. Part I: Description, J. Atmos. Sci., 62, 16651677, 2005.

Orville, H. D. and Kopp, F. J.: Numerical Simulation of the Life History of a Hailstorm, J. Atmos. Sci., 34, 1596-1618, 1977.

Phillips, V. T. J., Pokrovsky, A., and Khain, A.: The Influence of Time-Dependent Melting on the Dynamics and Precipitation Production in Maritime and Continental Storm Clouds, J. Atmos. Sci., 64, 338-359, 2007.

Pruppacher, H. R. and Klett, J. D.: Microphysics of Clouds and Precipitation, Kluwer Academic Publishers, Boston, USA, 976 pp., 1997.

Reisin, T., Levin, Z., and Tzivion, S.: Rain production in convective clouds as simulated in an axisymmetric model with detailed microphysics. Part I: description of the model, J. Atmos. Sci., 53, 497-519, 1996.

Rosenfeld, D., Lohmann, U., Raga, G. B., O’Dowd, C. D., Kulmala, M., Fuzzi, S., Reissell, A., and Andreae, M. O.: Flood or Drought: How do aerosols affect precipitation?, Science, 321, 1309-1313, 2008a.

Rosenfeld, D., Woodley, W. L., Axisa, D., Freud, E., Hudson, J. G., and Givati, A.: Aircraft measurements of the impacts of pollution aerosols on clouds and precipitation over the Sierra Nevada,
J. Geophys. Res., 113, D15203, doi:10.1029/2007JD009544, 2008 b.

Sandu, I., Brenguier, J., Geoffroy, O., Thouron, O., and Masson, V.: Aerosol impacts on the diurnal cycle of marine stratocumulus, J. Atmos. Sci., 65, 2705-2718, 2008.

Sassen, K., DeMott, P. J., Prospero, J. M., and Poellot, M. R.: Saharan dust storms and indirect aerosol effects on clouds: CRYSTAL-FACE results, Geophys. Res. Lett., 30, 1633-1736, doi:10.1029/2003GL017371, 2003.

Seifert, A., Khain, A., Pokrovsky, A., and Beheng, K.: A Comparison of Spectral Bin and Two-Moment Bulk Mixed-Phase Cloud Microphysics, Atmos. Res., 80, 146-66, 2006.

Seinfeld, J. H. and Pandis, S. N.: Atmospheric Chemistry and Physics, John Wiley and Sons, Inc., Hoboken, NJ, USA, 2 edn., 2006.

Skamarock, W. C., Klemp, J. B., Dudhia, J., Gill, D. O., Barker, D. M., Duda, M. G., Huang, X.-Y., Wang, W., and Powers, J. G.: A description of the advanced research WRF Version 3, National Center for Atmospheric Research, Boulder, Colorado, USA, 2008.

Stevens, B. and Feingold, G.: Untangling aerosol effects on clouds and precipitation in a buffered system, Nature, 461, 607-613, doi:10.1038/nature08281, 2009.

Stevens, B., Feingold, G., Cotton, W. R., and Walko, R. L.: Elements of the Microphysical Structure of Numerically Simulated Nonprecipitating Stratocumulus, J. Atmos. Sci., 53, 980-1006, 1996.

Teller, A. and Levin, Z.: The effects of aerosols on precipitation and dimensions of subtropical clouds: a sensitivity study using a numerical cloud model, Atmos. Chem. Phys., 6, 67-80, doi:10.5194/acp-6-67-2006, 2006.

Twomey, S.: The nuclei of natural cloud formation Part 2: The supersaturation in natural clouds and the variation of cloud droplet concentration, P. Appl. Geo., 43, 243-249, 1959.

Twomey, S.: The Influence of Pollution on the Shortwave Albedo of Clouds, J. Atmos. Sci., 34, 1149-1152, 1977.

Tzivion, S., Feingold, G., and Levin, Z.: An Efficient Numerical Solution to the Stochastic Collection Equation, J. Atmos. Sci., 44, 3139-3149, 1987.

Tzivion, S., Feingold, G., and Levin, Z.: The Evolution of raindrop spectra. Part II: collisional collection/breakup and evaporation in a rainshaft, J. Atmos. Sci., 46, 3312-3327, 1989.

Vali, G.: Remarks on the mechanism of atmospheric ice nucleation, in: Proceedings of the Eighth International Conference on $\mathrm{Nu}-$ cleation, St. Petersburg, Russia, 265-269, 1975.

Van den Heever, S. C. and Cotton, W. R.: Urban Aerosol Impacts on Downwind Convective Storms, J. Appl. Meteor. Clim., 46, 828-850, 2007.

Van den Heever, S. C., Carri, G. G., Cotton, W. R., DeMott, P. J., and Prenni, A. J.: Impacts of Nucleating Aerosol on Florida Storms. Part I: Mesoscale Simulations, J. Atmos. Sci., 63, 17521775, 2006.

vanZanten, M. C., Stevens, B., Vali, G., and Lenschow, D. H.: Observations of Drizzle in Nocturnal marine stratocumulus, J. Atmos. Sci., 62, 88-106, 2005.

Wang, H. and Feingold, G.: Modeling mesoscale cellular structures and drizzle in marine stratocumulus. Part I: Impact of drizzle on the formation and evolution of open cells, J. Atmos. Sci., 66, 3237-3256, 2009a. 
Wang, H. and Feingold, G.: Modeling mesoscale cellular structures and drizzle in marine stratocumulus. Part II: The microphysics and dynamics of the boundary region between open and closed cells, J. Atmos. Sci., 66, 3257-3275, 2009 b.

Wang, H., Feingold, G., Wood, R., and Kazil, J.: Modeling microphysical and meteorological controls on precipitation and cloud cellular structures in Southeast Pacific stratocumulus, Atmos. Chem. Phys., 10, 6347-6362, doi:10.5194/acp-10-6347-2010, 2010.
Weisman, M. L. and Klemp, J. B.: The dependence of numerically simulated convective storms on vertical wind shear and buoyancy, Mon. Weather Rev., 110, 504-520, 1982.

Xue, H., Teller, A., Rasmussen, R., Geresdi, I., and Pan, Z.: Effects of aerosol solubility and regeneration on warm-phase orographic clouds and precipitation simulated by a detailed bin microphysics scheme, J. Atmos. Sci., 67, 3336-3354, 2010. 